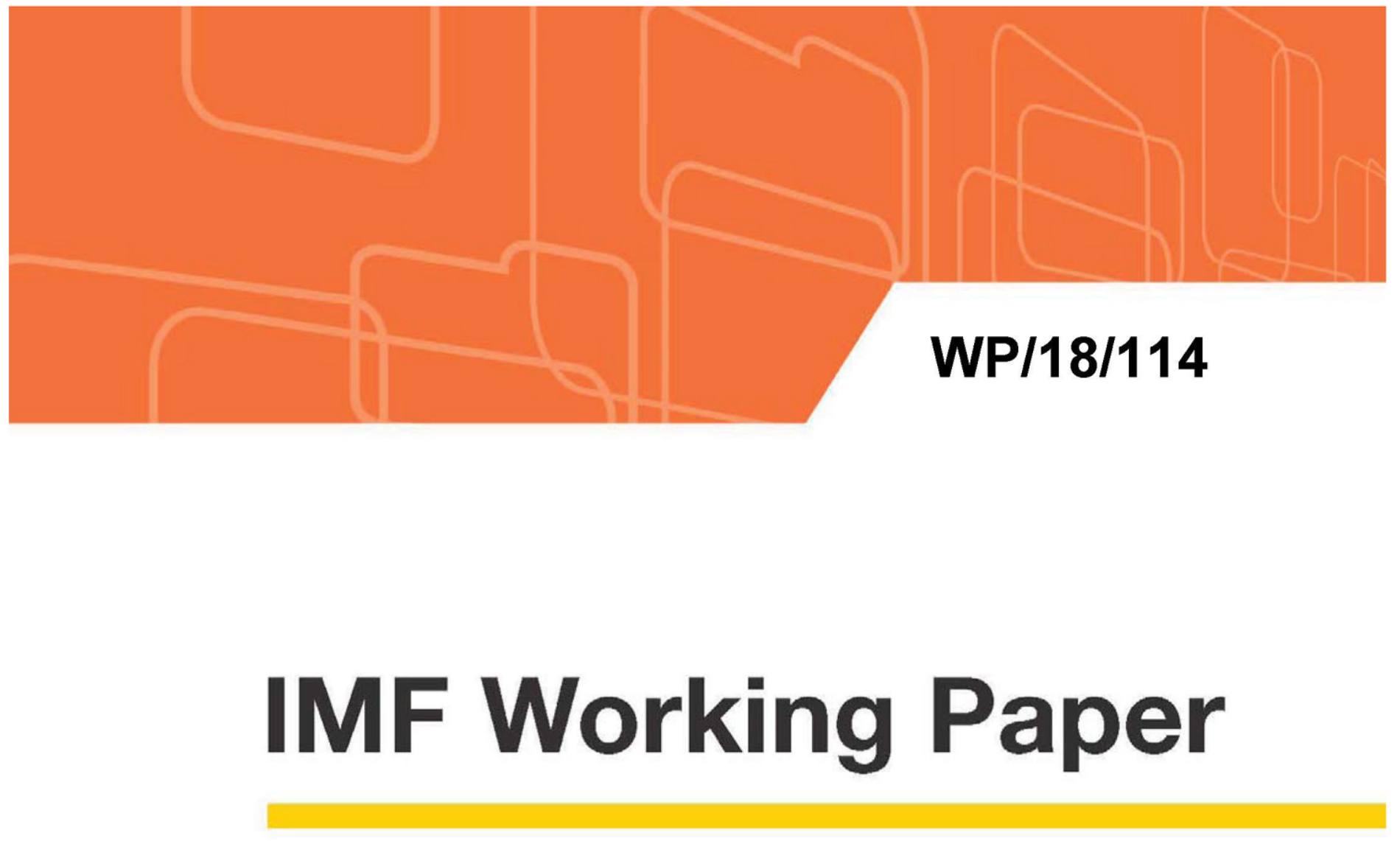

\title{
International Spillovers of Forward Guidance Shocks
}

by Callum Jones, Mariano Kulish, and Daniel M. Rees

IMF Working Papers describe research in progress by the author(s) and are published to elicit comments and to encourage debate. The views expressed in IMF Working Papers are those of the author(s) and do not necessarily represent the views of the IMF, its Executive Board, or IMF management. 


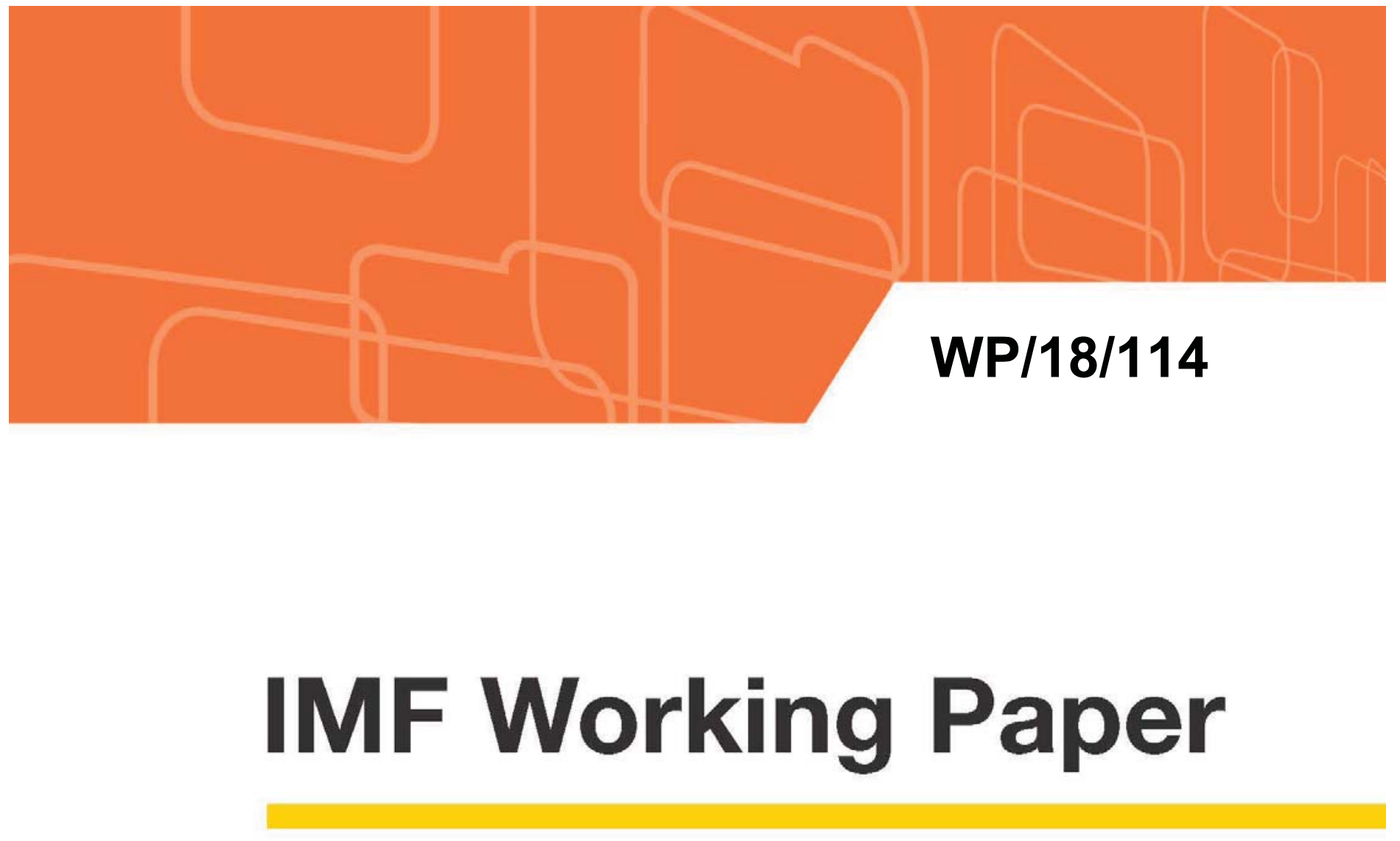

\section{International Spillovers of Forward Guidance Shocks}

by Callum Jones, Mariano Kulish, and Daniel M. Rees

IMF Working Papers describe research in progress by the author(s) and are published to elicit comments and to encourage debate. The views expressed in IMF Working Papers are those of the author(s) and do not necessarily represent the views of the IMF, its Executive Board, or IMF management.

I N T E R N A T I O N A L M O N E T A R Y F F N D 


\title{
IMF Working Paper
}

\author{
Research Department
}

\section{International Spillovers of Forward Guidance Shocks* Prepared by Callum Jones, Mariano Kulish ${ }^{\ddagger}$, and Daniel M. Rees ${ }^{\S}$}

Authorized for distribution by Luis Cubeddu

April 2018

\begin{abstract}
IMF Working Papers describe research in progress by the author(s) and are published to elicit comments and to encourage debate. The views expressed in IMF Working Papers are those of the author(s) and do not necessarily represent the views of the IMF, its Executive Board, or IMF management.
\end{abstract}

\begin{abstract}
After 2007, countries that cut their policy interest rates close to zero turned, among other policies, to forward guidance. We estimate a two-country model of the U.S. and Canada to quantify how unexpected changes in U.S. forward guidance affected Canada. Expansionary U.S. forward guidance shocks, like conventional policy shocks, are beggarthyneighbor and depress Canadian output, but by twice as much as conventional shocks. We find that the effect of U.S. forward guidance shocks on Canadian output, unlike conventional policy shocks, depends on the state of U.S. demand and can be five times smaller when U.S. demand is weak.
\end{abstract}

JEL Classification Numbers: E32, E52, F41.

Keywords: Forward Guidance, Spillovers, Unconventional Monetary Policy, Zero Lower Bound.

Authors’ E-Mail Addresses: cjones3@imf.org, mariano.kulish@sydney.edu.au, reesd@rba.gov.au

\footnotetext{
* We thank Pablo Cuba-Borda, Stanley Fischer, Matteo Iacoviello, Alejandro Justiniano, Greg Kaplan, Neil Mehrotra, Bruce Preston, Andrea Raffo, and seminar participants at the Federal Reserve Board, the Reserve Bank of Australia, Macquarie University, the University of Melbourne, and participants of the Fordham International Economics/Finance Workshop, the Australian Conference of Economists and the Macroeconomic Policy Meetings at the Melbourne Institute for useful comments and discussions. All remaining errors are ours. * School of Economics, The University of Sydney.

$\S$ Economic Analysis Department, Reserve Bank of Australia.
} 


\section{Introduction}

In response to the 2007-08 financial crisis, the Federal Reserve cut its policy interest rate to near zero and turned to unconventional monetary policies and, in particular, to forward guidance policy. The unprecedented monetary actions in the US provoked a debate about the effects of these policies on other open economies, which saw their currencies appreciate considerably against the US dollar. Rajan (2015), for instance, argues that the forward guidance policy of 'lower interest rates for longer' triggered international capital flows that, in a 'search for yield', appreciated non-US currencies and shifted spending away from domestically produced goods. In contrast, Bernanke (2017) argues that growth in the US during the recent recovery has not been driven by exports and that the 'expenditure-augmenting' effects of expansionary US monetary policies were likely to have added to global demand and to have counteracted the 'expenditure-switching' forces that were the concern of Rajan (2015).

The literature explores the competing mechanisms governing the strength and direction of international monetary policy spillovers for the design of optimal policy (Bodenstein et al., 2017; Haberis and Lipinska, 2012; Fujiwara et al., 2013). In these papers, a foreign monetary expansion affects small open economies through two channels; first, by increasing foreign output, and second, by appreciating the domestic currency. The trade elasticity of substitution between domestic and foreign goods is crucial for the transmission of monetary policy spillovers because, when domestic goods easily substitute for foreign goods, an exchange rate appreciation causes a decline in the demand for domestic goods that outweighs any increase due to an expanding foreign economy - a 'beggar-thy-neighbor' effect. But if the trade elasticity is low, higher demand from the foreign economy can outweigh the substitution effect induced by the exchange rate appreciation, so that domestic output can, in fact, increase with expansionary monetary policy abroad. The net effect of international monetary policy spillovers on domestic output is therefore, in theory, ambiguous.

The empirical evidence on the effects that conventional monetary policy in the US exerts on other countries is mixed. ${ }^{1}$ Furthermore, evidence on the effects from the unconventional monetary policy period in the US is limited to the study of quantitative easing policies on emerging markets using reduced form methods. ${ }^{2}$ To our knowledge, there is no evidence coming from the kind of structural models that the theoretical literature uses to highlight the

\footnotetext{
${ }^{1}$ See Ammer et al. (2016), Bernanke (2017), Dedola et al. (2017) and Kim (2001).

${ }^{2}$ See Anaya et al. (2017), Chen et al. (2016) and Tillmann (2016) for evidence that relies on vector autoregressions, and Chen et al. (2014) for regression evidence using an event-study type identification for monetary policy shocks.
} 
competing forces that are set in motion following a monetary policy expansion abroad, which is important because unconventional monetary policies work mainly through an expectations channel, which reduced form methods cannot account for. ${ }^{3}$ In fact, the 'Taper Tantrum' of 2013 revealed that attempts to separate balance sheet policies from market expectations of the path of interest rates failed despite the Federal Reserve's best efforts to communicate that short-term interest rates would remain low for a long time even after the tapering of asset purchases. $^{4}$ To our knowledge, this paper is the first to provide model-based evidence on the spillovers of the forward guidance policies of 'lower interest rates for longer' emphasized by Rajan (2015) and that the Federal Reserve used after 2009.

The model we use to quantify the international spillovers of forward guidance by the Federal Reserve is an extension of the canonical two-country small open economy model of Galí and Monacelli (2005). We apply the model to the US and Canada and focus on the period from 2009 to 2014. This period, as survey measures suggest, include the largest changes in the expected duration of the Federal Reserve zero interest rate policy. We choose Canada for two reasons. First, Canada is closely linked financially and through trade in goods and services with the US - around three quarters of Canada's merchandise exports go to the US, accounting for close to 20 per cent of its GDP. Second, the Bank of Canada followed closely US monetary policy after the crisis and responded with calendar-based forward guidance of its own in 2009 (see Murray, 2013). This provides us with a unique opportunity to quantify, in addition to the spillovers of the US forward guidance, the impact of domestic forward guidance on a small open economy as well. ${ }^{5}$

We use Bayesian methods to estimate, jointly, the parameters and expected durations of fixed interest rates, using US and Canadian data on output, inflation, and interest rates (both short-term and long-term interest rates). Estimation of structural models over samples that extend beyond 2009 requires accounting for a regime change in monetary policy, which we do using the method of Kulish, Morley and Robinson (2017). ${ }^{6}$ The interaction of forward-looking expectations and a lower bound on interest rates gives rise to a non-linear solution that makes the transmission of shocks during the period of fixed interest rates state-dependent. We extract the estimated model's structural shocks and remove the effect of forward guidance shocks using the piecewise-linear method to solve models with occasionally binding constraints

\footnotetext{
${ }^{3}$ See also Bernanke and Reinhart (2004) and Eggertsson and Woodford (2003).

${ }^{4}$ See Bernanke (2017).

${ }^{5}$ Following the classification of Campbell et al. (2012), our focus is on calendar-based 'Odyssean' forward guidance policies.

${ }^{6}$ In the case of Canada we estimate forward guidance at one per cent from 2010Q3 onwards.
} 
proposed by Jones (2017). ${ }^{7}$ This procedure allows us to distinguish between the estimated expected duration and the duration which is implied by treating the level of the fixed interest rate as an occasionally binding constraint given the structural shocks. We refer to the latter as the endogenous expected duration. If the central bank's forward guidance extends the duration of the fixed interest rate regime beyond what the constraint would have implied, the estimated duration would be greater than the endogenous duration.

As the theory emphasizes, the effect of foreign monetary policy on a small open economy is ambiguous. We first consider a simplified version of our estimated model in order to distill the transmission mechanism and identify the key parameters that govern the impact of monetary policy spillovers, namely the trade elasticity of substitution and the parameters governing the degree of price stickiness in both countries. In our estimation, we put wide enough priors over these parameters to accommodate both Bernanke (2017) and Rajan (2015)'s points of view and let the data speak through the lens of our model. Our estimates imply that 'expenditure switching' effects are stronger than 'expenditure augmenting' effects across the posterior range, so that expansionary US monetary policy is 'beggar-thy-neighbor' vis-a-vis Canada. As in Mundell-Fleming type models, we find using counterfactuals that although expansionary US monetary policy is found to be 'beggar-thy-neighbor', in aggregate the US and Canada are both better off by jointly responding with expansionary forward guidance to the large contractionary shocks that took place during the Great Recession. ${ }^{8}$

The expected durations of the fixed interest rate policy varied more in the US than they did in Canada. For the US, the estimated duration is larger than the endogenous duration, consistent with expansionary forward guidance. The degree of expansionary forward guidance was strongest between 2011 and 2013, consistent with the explicit calendar-based announcements made by the Federal Reserve. We also find forward guidance stimulus in Canada whereby the expected duration of fixed interest rates is longer than the duration implied by the estimated structural shocks.

We define a forward guidance shock as an exogenous change in the expected duration of the fixed interest rate regime. The estimated average change in the US forward guidance duration is around 2 quarters. A 2 quarter extension in the expected duration has an impact on output which is approximately that of a 2 standard deviation conventional monetary shock. But more importantly, the propagation of unconventional shocks is state-dependent. International spillovers depend on the state of the US preference shock: a large, negative

\footnotetext{
${ }^{7}$ See also Jones, Midrigan and Philippon (2017).

${ }^{8}$ For earlier discussions of these mechanisms in Mundell-Fleming-type models see Mundell (1968) chapter 18 and Eichengreen and Sachs (1985).
} 
state of the US preference shock diminishes the expansionary impact of an extension in the expected duration for the US as well as the implied contractionary effects for Canada.

We then use the estimated shocks to compute the counterfactual paths the economies would have followed absent forward guidance. We find a cumulative loss of output of $27 \%$ for the US and of 15\% for Canada, with the counterfactual decline in output in the US mainly occurring between 2011 and 2014, and between 2010 and 2012 for Canada. In a second counterfactual, we turn off the response of forward guidance in the US only but maintain it in Canada, and find that Canadian output would have been almost $4 \%$ higher, cumulatively.

The rest of the paper is structured as follows. Section 2 outlines the model and discusses the transmission in a simplified version. Section 3 discusses the solution and estimation method. Section 4 presents estimation results while Section 5 presents the cross-country effects of forward guidance in our estimated model. Section 6 concludes.

\section{Model}

We conduct our analysis using a small open economy model along the lines of Galí and Monacelli (2005). The model features two economies: a large (foreign) economy and a small (domestic) economy. Economic developments in the large economy affect the small economy, but the reverse is not true. As in De Paoli (2009a), the model is the limiting case of a two-country model where the relative size of one of the economies goes to zero. We extend this otherwise standard framework in four dimensions, including: (i) imperfect exchange rate pass-through; (ii) trend inflation; (iii) interest rates of longer maturities; and (iv) habits in the utility function. ${ }^{9}$

\subsection{The Large Economy}

This economy is populated by a large number of households who maximize:

$$
\mathbb{E}_{0} \sum_{t=0}^{\infty} \beta^{t}\left[\xi_{t}^{*}\left(\log \left(C_{t}^{*}-h C_{t-1}^{*}\right)-\frac{N_{t}^{*} 1+\varphi}{1+\varphi}\right)\right],
$$

where $N_{t}^{*}$ is labor supply and $\xi_{t}^{*}$ denotes intertemporal preference shocks that follow an $\operatorname{AR}(1)$

process in logs. $C_{t}^{*}$ is a composite consumption index given by $C_{t}^{*}=\left[\int_{0}^{1} C_{t}^{*}(i)^{\frac{\nu-1}{\nu}} d i\right]^{\frac{\nu}{\nu-1}}$, where $\nu$ is the elasticity of substitution between types of differentiated goods. Households face in every period $t$ the flow budget constraint:

$$
P_{t}^{*} C_{t}^{*}+\mathbb{E}_{t}\left\{Q_{t, t+1}^{*} D_{t+1}^{*}\right\} \leq D_{t}^{*}+W_{t}^{*} N_{t}^{*}+T_{t}^{*},
$$

\footnotetext{
${ }^{9}$ The final set of log-linear equations used in estimation is given in the Appendix.
} 
for all $t>0$, where $P_{t}^{*}$ is the large economy's CPI, $W_{t}^{*}$ is the nominal wage rate and $T_{t}^{*}$ denotes taxes and transfers. $D_{t+1}^{*}$ is the nominal payoff in period $t+1$ of the portfolio held at the end of period $t$ and $Q_{t, t+1}^{*}$ is the stochastic discount factor for one-period ahead nominal payoffs. Households have access to a complete set of internationally traded contingent claims.

Firms produce differentiated goods with the technology:

$$
Y_{t}^{*}(i)=Z_{t} A_{t}^{*} N_{t}^{*}(i)
$$

where $Y_{t}^{*}(i)$ is the production and $N_{t}^{*}(i)$ the labor input of firm $i . Z_{t}$ is the trend component of productivity, which follows a deterministic process that grows at the rate $\mu$, and $A_{t}^{*}$ is the transitory component of productivity, which follows an $\mathrm{AR}(1)$ process in logs. Real marginal costs are common across firms:

$$
M C_{t}^{*}=\frac{W_{t}^{*}}{P_{t}^{*} Z_{t} A_{t}^{*}}
$$

Firms face Calvo-style pricing frictions. Each quarter, a fraction of firms, $1-\theta^{*}$, sets prices optimally, while the remainder adjusts their prices by the steady-state inflation rate, $\Pi^{*}$. The pricing problem for a representative firm $i$ is:

$$
\max _{P_{t}^{*}(i)} \sum_{k=0}^{\infty}\left(\beta \theta^{*}\right)^{k} \mathbb{E}_{t}\left\{\frac{\Lambda_{t+k}^{*} P_{t}^{*}}{\Lambda_{t}^{*}}\left[\frac{P_{t}^{*}(i)\left(\Pi^{*}\right)^{k}}{P_{t+k}^{*}} Y_{t+k}^{*}(i)-M C_{t+k}^{*} Y_{t+k}^{*}(i)\right]\right\}
$$

subject to the demand constraint $Y_{t+k}^{*}(i)=\left[\frac{P_{t}^{*}(i)\left(\Pi^{*}\right)^{k}}{P_{t+k}^{*}}\right]^{-\chi} Y_{t+k}^{*}$, where $Y_{t+k}^{*}$ is aggregate output. In the expression above $\Lambda_{t}^{*}$ is the shadow value of an additional unit of nominal income in period $t$. Goods market clearing in the large economy requires that all production is consumed, that is $Y_{t}^{*}=C_{t}^{*}$.

When the interest rate is not fixed, monetary policy follows an interest rate rate rule that responds to inflation, output growth and the deviation of the level of output from trend:

$$
\frac{R_{t}^{*}}{R^{*}}=\left[\frac{R_{t-1}^{*}}{R^{*}}\right]^{\rho_{R}^{*}}\left[\left(\frac{\Pi_{t}^{*}}{\Pi^{*}}\right)^{\phi_{\pi}^{*}}\left(\frac{Y_{t}^{*}}{Y_{t-1}^{*} \mu}\right)^{\phi_{g}^{*}}\left(\frac{Y_{t}^{*}}{Z_{t}}\right)^{\phi_{y}^{*}}\right]^{1-\rho_{R}^{*}} \exp \left(\varepsilon_{R, t}^{*}\right)
$$

where $R_{t}^{*}$ is the policy rate in the large economy, $R^{*}=\mu \Pi^{*} / \beta$ is the steady-state policy rate and $\varepsilon_{R, t}^{*}$ is a monetary policy shock. After 2009Q1, the central bank fixes the level of the interest rate at $\bar{R}^{*}$, that is

$$
\frac{R_{t}^{*}}{R^{*}}=\bar{R}^{*}
$$

where $\bar{R}^{*}$ need not be the effective lower bound. In fact, for the US we set $\bar{R}^{*}$ to the mid point of the target range for the Federal Funds rate, to $0.125 \%$. 
Longer-term interest rates are determined via the expectations hypothesis. We link model longer-term interest rates to observed longer-term interest rates following Graeve et al. (2009). For any maturity $m>1$ :

$$
R_{m, t}^{*, \text { obs }}=R_{m, t}^{*} \exp \left(c_{m}^{*} \eta_{t}^{*} \varepsilon_{m, t}^{*}\right),
$$

where $R_{m, t}^{*}$ is the interest rate on a bond that pays one unit of the large economy's currency in $m$ quarters as determined by the expectations hypothesis, $c_{m}^{*}$ is a constant risk premia on the $m$ quarter interest rate, $\eta_{t}^{*}$ is shock, common to all interest rates in the large economy, that follows exogenous autoregressive process and $\varepsilon_{m, t}^{*}$ is an idiosyncratic shock to the $m$ quarter interest rate in the large economy. Because the expectations hypothesis holds, longer-term nominal interest rates in the model, $R_{m, t}$, are also subject to the lower bound of the short-rate $R_{t}^{*}$.

\subsection{The Small Economy}

The structure of the small economy is similar to that of the large economy, except that households consume goods and services produced abroad and firms sell their output overseas as well as domestically. Unless stated otherwise, variables have the same interpretation as in the large economy.

Households The small economy is populated by a representative household that maximizes the expected present discounted value of lifetime utility, given by:

$$
\mathbb{E}_{0} \sum_{t=0}^{\infty} \beta^{t}\left[\xi_{t}\left(\log \left(C_{t}-h C_{t-1}\right)-\frac{N_{t}^{1+\varphi}}{1+\varphi}\right)\right]
$$

subject to the flow budget constraint in every period $t$ :

$$
P_{t} C_{t}+\mathbb{E}_{t}\left\{Q_{t, t+1} D_{t+1}\right\} \leq D_{t}+W_{t} N_{t}+T_{t} .
$$

As in the large economy, households have access to a complete set of internationally traded contingent claims. Complete markets and household optimization implies a risk-sharing condition linking the marginal utilities of consumption in the large and small economies,

$\Lambda_{t}=\frac{\Lambda_{t}^{*}}{Q_{t}}$ where $\Lambda_{t}$ is the marginal value of an additional unit of domestic nominal income to households in the small economy, $Q_{t}=S_{t} P_{t}^{*} / P_{t}$ is the real exchange rate between the small and large economy and $S_{t}$ is the nominal exchange rate between the small and large economy. The exchange rate is defined as the number of units of the small economy's currency required to purchase one unit of the large economy's currency. According to this definition, an increase 
in $S_{t}$ corresponds to a depreciation of the domestic currency. To account for deviations from uncovered interest rate parity in estimation, we add a risk premium shock to the risk-sharing condition that follows an $\mathrm{AR}(1)$ process in logs.

Consumption Retailers The final consumption good is assembled by perfectly competitive retailers using the technology:

$$
C_{t}=\left[(1-\alpha)^{\frac{1}{\tau}}\left(C_{H, t}\right)^{\frac{\tau-1}{\tau}}+\alpha^{\frac{1}{\tau}}\left(C_{F, t}\right)^{\frac{\tau-1}{\tau}}\right]^{\frac{\tau}{\tau-1}}
$$

where $C_{H, t}$ and $C_{F, t}$ are composite consumption indices of domestically- and foreign- produced final goods. The parameter $\tau$ is the elasticity of substitution between domestic- and foreignproduced goods. The price index corresponding to this bundle is:

$$
P_{t}=\left[(1-\alpha)\left(P_{H, t}\right)^{1-\tau}+\alpha\left(P_{F, t}\right)^{1-\tau}\right]^{\frac{1}{1-\tau}}
$$

where $P_{H, t}$ is the price of the domestic composite good and $P_{F, t}$ is the price of the imported composite good, both expressed in domestic currency.

Domestic Final Goods Retailers The domestically-produced final good, $Y_{H, t}$ is assembled by a perfectly competitive final good retailer that combines domestically-produced intermediate goods using the technology:

$$
Y_{H, t}=\left[\int_{0}^{1} Y_{H, t}(i)^{\frac{\chi-1}{\chi}} d i\right]^{\frac{\chi}{\chi-1}},
$$

where $\chi$ is the elasticity of substitution between varieties of domestic intermediate goods. The price of the domestic final good is:

$$
P_{H, t}=\left[\int_{0}^{1} P_{H, t}(i)^{1-\chi} d i\right]^{\frac{1}{1-\chi}} .
$$

It follows that the final goods firm's demand for each variety is given by:

$$
Y_{H, t}(i)=\left(\frac{P_{H, t}(i)}{P_{H, t}}\right)^{-\chi} Y_{H, t} .
$$

Domestic Intermediate Goods Producers Domestic intermediate goods producers manufacture heterogeneous goods using the technology:

$$
Y_{H, t}(i)=Z_{t} A_{t} N_{t}(i)
$$


where $A_{t}$ is a stationary technology process that follows an $\mathrm{AR}(1)$ process in logs. Real marginal costs are equal across firms and given by:

$$
M C_{t}=\frac{W_{t}}{P_{t} Z_{t} A_{t}}
$$

As for the US, firms in Canada face Calvo-style pricing frictions so that, each quarter, a fraction, $1-\theta$, of firms are able to adjust their prices freely. The remaining firms index their prices to the steady-state inflation rate, $\Pi$. The resulting pricing problem for firm $i$ is

$$
\max _{P_{H, t}(i)} \sum_{k=0}^{\infty}(\beta \theta)^{k} \mathbb{E}_{t}\left\{\frac{\Lambda_{t+k} P_{t}}{\Lambda_{t}}\left[\frac{P_{H, t}(i) Y_{H, t+k}(i) \Pi^{k}}{P_{t+k}}-M C_{t+k} Y_{H, t+k}(i)\right]\right\}
$$

subject to the domestic final goods demand condition given above.

Exporters Exporters purchase the domestic final good at price $P_{H, t}$ and differentiate it through branding for sale in the foreign economy. The exporters are owned by domestic households. However, as in Burgess et al. (2013), all export contracts and prices are specified in the currency of the large economy. An export retailer bundles these goods before selling them overseas according to the technology:

$$
X_{t}=\left[\int_{0}^{1} X_{t}(i)^{\frac{\nu_{X}-1}{\nu_{X}}}(i)\right]^{\frac{\nu_{X}}{\nu_{X}-1}}
$$

where $\nu_{X}$ is the elasticity of substitution between different varieties for export. The corresponding price index, in foreign currency terms, is:

$$
P_{X, t}^{*}=\left[\int_{0}^{1} P_{X, t}^{*}(i)^{1-\nu_{X}} d i\right]^{\frac{1}{1-\nu_{X}}} .
$$

The export retailer faces the demand function:

$$
X_{t}=\left(\frac{P_{X, t}^{*}}{P_{t}^{*}}\right)^{-\tau} Y_{t}^{*}
$$

As in Justiniano and Preston (2010) the elasticity of export demand, $\tau$, is the same as the elasticity of substitution between domestic and foreign goods in the consumption basket. This implies that household's preferences in the small and large economies are the same, which for the US and Canada is a reasonable assumption. It follows that the demand for each exporter's goods are given by:

$$
X_{t}(i)=\left(\frac{P_{X, t}^{*}(i)}{P_{X, t}^{*}}\right)^{-\nu_{X}} X_{t}
$$


Exporters face Calvo-style pricing frictions, with $1-\theta_{x}$ governing the share of firms that are able to adjust their prices each quarter. The resulting pricing problem for firm $i$ is:

$$
\max _{P_{X, t}^{*}(i)} \sum_{k=0}^{\infty}\left(\beta \theta_{x}\right)^{k} \mathbb{E}_{t}\left\{\frac{\Lambda_{t+1} P_{t}}{\Lambda_{t}}\left[\frac{P_{X, t}^{*}(i) \Pi^{k} X_{t+k}(i)}{S_{t+k} P_{t+k}}-\frac{P_{H, t+k} X_{t+k}(i)}{P_{t+k}}\right]\right\},
$$

subject to the demand constraint given above.

Finally, market clearing for the domestic final good requires that all production is sold, either domestically or overseas. That is:

$$
Y_{H, t}=C_{H, t}+X_{t}
$$

Importers Importers bring in homogeneous products from abroad at price $S_{t} P_{t}^{*}$ and differentiate them through branding. Importers then sell the differentiated goods to a retailer that combines them into the final imported good using the technology:

$$
C_{F, t}=\left[\int_{0}^{1} C_{F, t}(i)^{\frac{\nu_{F}-1}{\nu_{F}}} d i\right]^{\frac{\nu_{F}}{\nu_{F}-1}}
$$

where $C_{F, t}(i)$ is the quantity of the imported good of variety $i$ used in the production of the final imported good and $\nu_{F}$ is the elasticity of substitution between different imported good varieties. The price index corresponding to the imported final good is:

$$
P_{F, t}=\left[\int_{0}^{1} P_{F, t}(i)^{1-\nu_{F}} d i\right]^{\frac{1}{1-\nu_{F}}} .
$$

Consequently, each importer faces the demand curve:

$$
C_{F, t}(i)=\left(\frac{P_{F, t}(i)}{P_{F, t}}\right)^{-\nu_{F}} C_{F, t} .
$$

Importers face Calvo-style pricing frictions. Each quarter, a fraction, $1-\theta_{m}$ sets prices optimally, while the remainder adjusts their prices by the small economy's steady-state inflation rate, $\Pi$. The pricing problem for a representative firm $i$ is:

$$
\max _{P_{F, t}(i)} \sum_{k=0}^{\infty}\left(\beta \theta_{m}\right)^{k} \mathbb{E}_{t}\left\{\frac{\Lambda_{t+1} P_{t}}{\Lambda_{t}}\left[\frac{P_{F, t}(i) C_{F, t}(i) \Pi^{k}}{P_{t+k}}-\frac{S_{t+k} P_{t+k}^{*} C_{F, t+k}(i)}{P_{t+k}}\right]\right\},
$$

subject to the demand constraint above.

Monetary Policy Before 2009Q2, when $R_{t}$ is not fixed, the Canadian central bank follows the feedback rule:

$$
\frac{R_{t}}{R}=\left[\frac{R_{t-1}}{R}\right]^{\rho_{R}}\left[\left(\frac{\Pi_{t}}{\Pi}\right)^{\phi_{\pi}}\left(\frac{Y_{H, t}}{Y_{H, t-1} \mu}\right)^{\phi_{g}}\left(\frac{Y_{H, t}}{Z_{t}}\right)^{\phi_{y}}\right] e^{\varepsilon_{R, t}} .
$$


As for the US, we allow for an arbitrary level of the fixed nominal interest rate. Canada fixed its policy rate at $0.25 \%$ for a year and then at $1 \%$ for about 5 years in our sample so, from 2009Q2, policy follows

$$
\frac{R_{t}}{R}=\bar{R}
$$

and from 2010Q3

$$
\frac{R_{t}}{R}=\overline{\bar{R}}
$$

The term structure of interest rates in the small economy is determined in a similar manner to the large economy. For any $m>1$ :

$$
R_{m, t}^{\mathrm{obs}}=R_{m, t} \exp \left(c_{m} \eta_{t} \varepsilon_{m, t}\right)
$$

where $R_{m, t}$ is the interest rate on a bond that pays one unit of domestic currency in $m$ quarters as determined by the expectations hypothesis, $c_{m}$ is a constant risk premia on the $m$ quarter interest rate, $\eta_{t}$ is shock, common to all small economy interest rates, that follows an exogenous autoregressive process and $\varepsilon_{m, t}$ is an idiosyncratic shock to the $m$ quarter interest rate in the small economy.

\subsection{The Transmission of Foreign Monetary Policy}

In the empirical implementation, we use the model that we describe above. But to understand the key forces that determine the strength of foreign monetary policy shocks in the larger model it is useful to consider the impact of foreign shocks in a simpler context. With three simplifying assumptions - no habits in consumption, complete exchange rate pass through at home and abroad and i.i.d. shock processes - our small economy model collapses to that of De Paoli (2009b) which can be characterized by the set of log-linear equations:

$$
\begin{aligned}
\pi_{t} & =\kappa\left(c_{t}+\varphi y_{H, t}+\frac{\alpha}{1-\alpha} q_{t}\right)+\beta \mathbb{E}_{t} \pi_{t+1} \\
y_{H, t} & =(1-\alpha) c_{t}+\alpha y_{t}^{*}+\gamma q_{t} \\
c_{t} & =y_{t}^{*}+q_{t} \\
c_{t} & =-\left(r_{t}-\mathbb{E}_{t} \pi_{t+1}\right)+\mathbb{E}_{t} c_{t+1}
\end{aligned}
$$

and a monetary policy reaction function. In the equations above, variables represent percentage deviations from steady state, $\gamma=\frac{\tau \alpha(2-\alpha)}{(1-\alpha)}$ and $\kappa=\frac{(1-\theta \beta)(1-\theta)}{(1+\chi \varphi) \theta}$. The only exogenous shock is $y_{t}^{*}$. Although this system of equations does not feature foreign interest rates, it can nonetheless be used to examine foreign monetary policy spillovers following foreign monetary policy shocks, conditional on the response of foreign output, $y_{t}^{*}$. 
First, assume that domestic monetary policy follows a rule of the form:

$$
r_{t}=\phi_{\pi} \mathbb{E}_{t} \pi_{t+1}
$$

where $\phi_{\pi}>1$. Because the shock is i.i.d., this reaction function implies that the small economy's central bank stabilizes the ex-ante real interest rate. One can think of this exercise as illustrating the direct effects of a foreign monetary policy shock, holding the stance of domestic monetary policy fixed.

The monetary policy rule and Euler equation imply that the level of consumption in the small economy is stable at its steady state level. The risk sharing condition then ensures that the small economy's real exchange rate appreciates one-for-one with increases in foreign output. Substituting these results into the resource constraint, we can express output in the small economy as a function of foreign output:

$$
y_{H, t}=\left[\alpha-\frac{\tau \alpha(2-\alpha)}{1-\alpha}\right] y_{t}^{*}
$$

The expression in brackets summarizes the two forces that govern the response of domestic output. The first term, $\alpha y_{t}^{*}$, is the income effect - the direct increase in exports from the small economy resulting from expansionary monetary policy abroad that increases demand in the large economy. This term is increasing in the openness of the domestic economy, reflected in the parameter $\alpha$. The second term, $\frac{\tau \alpha(2-\alpha)}{1-\alpha} y_{t}^{*}$, is the substitution effect - the reduction in demand for goods produced in the small economy resulting from expansionary monetary policy abroad that triggers an appreciation of the small economy's real exchange rate. The strength of this term is increasing in the openness of the domestic economy, as well as in the substitutability between domestic and foreign products, reflected in the parameter $\tau$. In the case where the domestic central bank perfectly stabilizes the real interest rate, foreign monetary policy is beggar-thy-neighbour if $\tau>\frac{1-\alpha}{2-\alpha}$.

The mechanism described above also summarizes the effect of foreign forward guidance shocks on the domestic economy. With a constant ex-ante real interest rate, Equation (34) describes the relationship between domestic and foreign output in each period. An announcement about the future path of interest rates in the foreign economy triggers a sequence of foreign output realizations. These realizations will expand or contract domestic output over time according to the path of foreign output and the relative strength of the income and substitution effects.

If the domestic central bank follows a reaction function that responds to current realizations 
of domestic inflation:

$$
r_{t}=\phi_{\pi} \pi_{t}
$$

then the real interest rate is no longer constant and the relationship between foreign and domestic output depends also on the flexibility of domestic prices, on the response of domestic marginal costs to demand conditions, and on the response of monetary policy to inflation, summarized by the following equation: ${ }^{10}$

$$
y_{H, t}=\left[\alpha-(1-\alpha+\gamma) \phi_{\pi} b-\frac{\tau \alpha(2-\alpha)}{1-\alpha}\right] y_{t}^{*}
$$

Although neat analytical expressions are not available in this case, Equation (36) reveals which additional parameters - in particular, the elasticity of labor supply, the slope of the Phillips curve and the strength of the monetary policy response to inflation - also matter in determining the extent to which foreign monetary policy is beggar-thy-neighbour.

A lower wage elasticity of labor supply (a lower value of $\varphi$ ) implies that wages, and hence marginal costs, are more responsive to changes in labor demand. Hours worked, in contrast, are less responsive. Foreign monetary policy is less beggar-thy-neighbour when the elasticity of labor supply is low.

When prices are more flexible (a larger value of $\kappa$ ) a given change in marginal costs translates more into changes in prices and less into changes in quantities. In the case where expansionary foreign monetary policy triggers a fall in domestic output, more flexible prices dampen the expenditure switching channel. This is because the fall in labor demand and marginal costs translates into a larger reduction in the prices of domestically-produced goods. This cushions the fall in the consumption of domestic goods.

A central bank that responds to inflation will cut interest rates following an expansionary foreign monetary policy shock that lowers domestic production, wages and inflation. In doing so, the central bank reduces the interest rate differential between the domestic and foreign economies and diminishes the initial exchange rate appreciation of the domestic currency. This too will reduce the extent to which expansionary foreign monetary policy is beggar-thy-neighbour.

The mechanisms described above are also at work in our larger model. In estimation, we place priors over the parameters that govern the response of domestic output to foreign monetary policy disturbances, in particular the trade elasticity, $\tau$, that are wide enough to allow the data to explain whether expansionary foreign monetary policy is also expansionary for the domestic economy, or beggar-thy-neighbour.

\footnotetext{
${ }^{10}$ Where $b=\frac{\varphi(\alpha-\gamma)-\frac{\alpha}{1-\alpha}}{\frac{1}{\kappa}+\varphi\left(1+\varphi(1-\alpha)+\varphi \gamma+\frac{\alpha}{1-\alpha}\right)}$ and $\gamma=\frac{\tau \alpha(2-\alpha)}{1-\alpha}$.
} 


\section{Solution and Estimation Methods}

Our problem is nonstandard because our model is one in which the policy interest rates in the US and Canada can be fixed at different periods, or at the same time. This section describes our approximate solution for the model with fixed interest rate regimes in our two-country setup.

\subsection{Solution for a Given Duration}

We use the solution methods proposed in Cagliarini and Kulish (2013), Kulish and Pagan (2017) and Jones (2017), which are related to the methods in Eggertsson and Woodford (2003) and Guerrieri and Iacoviello (2015), and the estimation method of Kulish, Morley and Robinson (2017). The Appendix provides additional details. ${ }^{11}$

Our model can be in one of the following four possible regimes at a given point in our sample: i) interest rates follow feedback rules, ii) only the interest rate of the large economy is fixed, iii) only the interest rate of the small economy is fixed, and iv) both interest rates are fixed. Figure 1 illustrates one possibility, in which in an initial sub-sample conventional policy applies to both economies, then there is a period of time for which the interest rate is fixed only in the large economy. After that, interest rates are fixed in both economies, and eventually there is a return to conventional policy which takes place out-of-sample.

We first linearize the model around the steady state for which policy rates follow feedback rules, and write the resulting system of equations in matrix form as:

$$
\mathbf{A} x_{t}=\mathbf{C}+\mathbf{B} x_{t-1}+\mathbf{D} \mathbb{E}_{t} x_{t+1}+\mathbf{F} \varepsilon_{t}
$$

where $x_{t}$ is the state vector and $\varepsilon_{t}$ is the vector of structural shocks, which we take to be i.i.d. without loss of generality. If it exists and is unique, the standard rational expectations solution to (37) is $x_{t}=\mathbf{J}+\mathbf{Q} x_{t-1}+\mathbf{G} \varepsilon_{t}$.

When only the foreign interest rate is fixed the structural equations are given by:

$$
\mathbf{A}^{*} x_{t}=\mathbf{C}^{*}+\mathbf{B}^{*} x_{t-1}+\mathbf{D}^{*} \mathbb{E}_{t} x_{t+1}+\mathbf{F}^{*} \varepsilon_{t}
$$

where the only equation that has changed in the starred system relative to (37) is the equation defining the foreign policy interest rate rule, which is now specified such that the nominal

\footnotetext{
${ }^{11}$ These methods have more general application than the context we are considering, and can be applied to a range of problems in which one requires to solve a model subject to occasionally binding constraints or anticipated changes in the structural parameters efficiently.
} 
interest rate is fixed. ${ }^{12}$

When only the domestic interest rate is fixed the structural equations are given by:

$$
\overline{\mathbf{A}} x_{t}=\overline{\mathbf{C}}+\overline{\mathbf{B}} x_{t-1}+\overline{\mathbf{D}} \mathbb{E}_{t} x_{t+1}+\overline{\mathbf{F}} \varepsilon_{t}
$$

where the only equation that has changed relative to (37) is the equation defining the domestic policy interest rate rule, which is now specified such that the nominal interest rate is fixed.

And when both foreign and domestic interest rates are fixed the structural equations are given by:

$$
\overline{\mathbf{A}}^{*} x_{t}=\overline{\mathbf{C}}^{*}+\overline{\mathbf{B}}^{*} x_{t-1}+\overline{\mathbf{D}}^{*} \mathbb{E}_{t} x_{t+1}+\overline{\mathbf{F}}^{*} \varepsilon_{t} .
$$

Because at least one nominal interest rate is fixed in regimes (38), (39) or (40), if any of these regimes were expected to prevail indefinitely in our model, they would be found to be inconsistent with a unique rational expectations solution. ${ }^{13}$ However, provided both nominal interest rates are expected to be governed by policy rules consistent with a unique solution, there is a unique path under temporarily fixed interest rates (Cagliarini and Kulish, 2013).

In general, the structural equations in-sample may be written:

$$
\mathbf{A}_{t} x_{t}=\mathbf{C}_{t}+\mathbf{B}_{t} x_{t-1}+\mathbf{D}_{t} \mathbb{E}_{t} x_{t+1}+\mathbf{F}_{t} \varepsilon_{t} .
$$

where $\left\{\mathbf{A}_{t}, \mathbf{C}_{t}, \mathbf{B}_{t}, \mathbf{D}_{t}, \mathbf{F}_{t}\right\}_{t=1}^{T}$ is a sequence of structural matrices over the sample. For example, if interest rates follow feedback rules at time $t$, then $\mathbf{A}_{t}=\mathbf{A}, \mathbf{C}_{t}=\mathbf{C}, \mathbf{B}_{t}=\mathbf{B}$, and so. If both domestic and foreign policy interest rates are fixed then $\mathbf{A}_{t}=\overline{\mathbf{A}}^{*}, \mathbf{C}_{t}=\overline{\mathbf{C}}^{*}$, $\mathbf{B}_{t}=\overline{\mathbf{B}}^{*}$, and so on.

Now suppose that at period $t^{\prime}$ feedback rules are expected to govern monetary policy from some future period $T^{\prime}$ onwards. Agents anticipate how the structural matrices will evolve until then. Say agents foresee that the structural equations will evolve as follows $\left\{\mathbf{A}_{t}, \mathbf{C}_{t}, \mathbf{B}_{t}, \mathbf{D}_{t}, \mathbf{F}_{t}\right\}_{t=t^{\prime}}^{T^{\prime}}$. Following Kulish and Pagan (2017), the solution may be written as a time-varying VAR of the form:

$$
x_{t}=\mathbf{J}_{t}+\mathbf{Q}_{t} x_{t-1}+\mathbf{G}_{t} \varepsilon_{t},
$$

given perfect foresight of the evolution of the structure of the economy. For this to be a rational expectations solution, expectations must satisfy (41) in all periods $t$. Equation (42)

\footnotetext{
${ }^{12}$ Notice that the notation can accommodate additional structural changes which have to be accounted for if the expansion point of the approximation changes. In our application we work around the intended steady state.

${ }^{13}$ This is the case in our model where monetary policy is 'active' in the terminology of Leeper (1991). As emphasized recently by Cochrane (2014), a fixed interest rate need not imply indeterminacy in models with 'active' fiscal policy.
} 
implies that expectations are $\mathbb{E}_{t} x_{t+1}=\mathbf{J}_{t+1}+\mathbf{Q}_{t+1} x_{t}$. Substituting expectations into (41) implies that at period $t$ :

$$
\mathbf{A}_{t} x_{t}=\mathbf{C}_{t}+\mathbf{B}_{t} x_{t-1}+\mathbf{D}_{t}\left(\mathbf{J}_{t+1}+\mathbf{Q}_{t+1} x_{t}\right)+\mathbf{F}_{t} \varepsilon_{t} .
$$

Which implies by undetermined coefficients the following recursions:

$$
\begin{aligned}
\mathbf{J}_{t} & =\left[\mathbf{A}_{t}-\mathbf{D}_{t} \mathbf{Q}_{t+1}\right]^{-1}\left(\mathbf{C}_{t}+\mathbf{D}_{t} \mathbf{J}_{t+1}\right) \\
\mathbf{Q}_{t} & =\left[\mathbf{A}_{t}-\mathbf{D}_{t} \mathbf{Q}_{t+1}\right]^{-1} \mathbf{B}_{t} \\
\mathbf{G}_{t} & =\left[\mathbf{A}_{t}-\mathbf{D}_{t} \mathbf{Q}_{t+1}\right]^{-1} \mathbf{F}_{t}
\end{aligned}
$$

The backward recursion for the sequence of time-varying reduced form matrices, $\left\{\mathbf{Q}_{t}\right\}_{t=t^{\prime}}^{T^{\prime}-1}$ starts from the terminal condition $\mathbf{Q}_{T^{\prime}}=\mathrm{Q}$ and works its way back to period $t^{\prime}$, yielding the system of time-varying reduced form matrices corresponding to (42). With the sequence for $\mathbf{Q}_{t}$ in hand, the sequence for $\mathbf{G}_{t}$ may computed as well as the sequence for $\mathbf{J}_{t}$ given the terminal condition $\mathbf{J}_{T^{\prime}}=\mathbf{J}$. Note that the terminal conditions, $\mathbf{J}$ and $\mathbf{Q}$, correspond to the solution matrices to the model around the steady state for which feedback rules for policy interest rates apply, consistent with the assumption that agents do not expect interest rates to be fixed from period $T^{\prime}$ onwards.

\subsection{Endogenous Durations}

Equation (42) is the solution for the case in which agents anticipate a sequence of given fixed interest rates at time period $t^{\prime}$. These fixed interest rate durations, however, may or may not be those implied by the structural shocks that have hit the economy up to $t^{\prime}$ if we were to treat the level of the fixed interest rate as a lower bound constraint. We use an algorithm to find, at each point in time, the duration which is consistent with fixed interest rates as lower bound constraints by using the solution above iteratively under the assumption of no future shocks. ${ }^{14}$

In our model, unanticipated shocks at time period $t^{\prime}+1$ could imply expected fixed interest rate durations at $t^{\prime}+1$ that are different to those that were expected at $t^{\prime}$. We refer to the fixed interest rate duration which is due to shocks alone as the endogenous duration and compute it at time period $t^{\prime}$ as follows. We describe the algorithm as it applies to the US. We know the state $x_{t^{\prime}-1}$ and the shocks $\varepsilon_{t^{\prime}}$. We first compute a forecast under the assumption

\footnotetext{
${ }^{14}$ To decompose the expected duration, we use the method of Jones (2017) for occassionally binding constraints, which is independent and contemporaneous to that of Guerrieri and Iacoviello (2015) and has also been used by Jones, Midrigan and Philippon (2017).
} 
that interest rates do not face a lower bound constraint at the level at which it is fixed. We then examine the forecast path of the nominal rate for violations of the constraint. If the path of the nominal interest rate contains values below the bound, we set the nominal interest rate to its bound but only for the first period that the bound is violated. We then apply the solution for a fixed interest rate regime that was discussed above. That solution implies a new forecast path for the nominal interest rate that must be examined for additional violations. Iterating in this way we arrive at a duration of the fixed interest rate at $t^{\prime}$ which is consistent with state $x_{t^{\prime}-1}$ and shocks $\varepsilon_{t^{\prime}}$. As shocks unfold in $t^{\prime}+1$ one recomputes the duration. The solution satisfies the constraint and captures, at each point in time, agents' forecasts of when the constraint is expected to bind. The Appendix describes the algorithm in full. Jones (2017) shows that this solution constitutes a good approximation to the non-linear economy.

The block-exogeneity of the two-country model allows us to find the endogenous durations of the US first and then take those as given when computing the durations for Canada.

\subsection{Identification of Forward Guidance}

Forward guidance is identified as follows. First, the model is estimated to get estimates of the durations and of the shocks. Then the method in section 3.2 is used to compute the endogenous durations that correspond with the estimated shocks. For each quarter of the fixed interest rate, the total estimated duration is decomposed into a duration implied by a lower bound constraint (the endogenous duration) and an additional duration. This additional duration captures other factors such as announcements intended to extend the duration of the fixed interest rate regime beyond the period implied by the constraint itself. ${ }^{15}$ We therefore identify forward guidance as the difference between the total estimated duration and the endogenous duration. This decomposition characterizes monetary policy when the policy rate is fixed and is useful since the level of the nominal interest rate, when constant, is alone an insufficient statistic of the stance of monetary policy.

Figure 2 illustrates how the decomposition is computed at each point in time. Say that at period $t^{\prime}$ the estimated duration of the lower bound is 5 quarters, so that the lower bound is expected to bind from period $t^{\prime}$ to period $t^{\prime}+4$. We use the Kalman smoother to obtain an estimate of the structural shocks $w_{t^{\prime}}$ prevailing at time period $t^{\prime}$. Using those shocks, we use the algorithm described above to obtain a forecast of the nominal interest rate. In Figure 2, we call this the 'endogenous forecast'. Associated with this forecast is an endogenous

\footnotetext{
${ }^{15}$ Other factors beyond explicit central bank communication can influence the duration. As is well known, markets reassessed the time of lift-off as the Federal Reserve was tapering the rate of bond purchases (taper-tantrum).
} 
duration of the lower bound, illustrated by the $\{3,2,1\}$ sequence of durations, the black bars in the bottom panel of Figure 2. Comparing this sequence with the sequence which would be expected given the estimated duration at $t^{\prime}$, in this case $\{5,4,3,2,1\}$, we identify forward guidance components of $\{2,2,2,2,1\}$. So at $t^{\prime}$ the total duration of 5 quarters is 3 quarters shocks and 2 quarters forward guidance. Unanticipated shocks that hit in $t^{\prime}+1$ do not influence the decomposition at $t^{\prime}$, but may well change the decomposition relative to the $t^{\prime}+1$ decomposition that was predicted at $t^{\prime}$. So the decomposition is recomputed at each point in time.

\subsection{The Likelihood Function}

Since (42) is a linear system, the Kalman filter can be used to construct the likelihood. When the interest rate is fixed, implicit in the evolution of the structural matrices are expected sequences of fixed rate durations. This means that the likelihood is a function both of the structural parameters and the sequences of expected durations. Following Kulish, Morley and Robinson (2017) we estimate jointly the structural parameters and durations of the fixed interest rate regimes in the large and small economies. ${ }^{16}$ Importantly, as in Kulish, Morley and Robinson (2017), the restriction that the durations must match the duration implied by shocks themselves is not imposed in estimation. It is important to not impose those constraints in estimation in light of the optimal policy prescription of Eggertsson and Woodford (2003) of extending the duration of the zero interest rate policy beyond the horizon implied by a lower bound constraint itself.

\section{Estimation}

\subsection{Data}

For estimation, we use US and Canadian nominal interest rates, output growth, and inflation, and changes in the US/Canadian nominal exchange rate. These seven quarterly data series are plotted in Figure 3. We also use 2-year nominal interest rates for both the US and Canada in helping identify the fixed interest rate durations. The series start in 1984Q1 and end in 2014Q4. All details of the data are provided in the Appendix.

\footnotetext{
${ }^{16}$ Details of the Kalman filter and Kalman smoother are relegated to the Appendix.
} 


\subsection{Assigned and Calibrated Parameters}

We calibrate a number of structural parameters in line with values from the literature. The quarterly discount factor $\beta$, common to both countries, is set at 0.9978 . The consumption habit formation parameter $h$ is set at 0.71 , the posterior mode of the estimated value in Smets and Wouters (2007), while the inverse of the Frisch elasticity of labor supply $\psi$, is calibrated to 1.5 in both countries, close to the values estimated in Smets and Wouters (2007) and Justiniano and Preston (2010). And the import share of the Canadian consumption basket, $\alpha$, is set to 0.29 to match the average share of exports and imports to Canadian GDP.

\subsection{Fixed Interest Rate Regimes}

We measure expected durations in the US from the time at which the Federal Funds rate reached $0.125 \%$ in 2009Q1 until the end of our sample 2014Q4. Similarly, we measure these durations in Canada when the policy rate was at 0.25\% between 2009Q2 and 2010Q2, and then when the rate was at 1\% between 2010Q3 and the end of the sample. This modeling choice is motivated by the clear communication of the Bank of Canada providing forward guidance of its fixed interest rate policy at these values over the sample period. ${ }^{17}$

\subsection{Estimation Results}

Structural Parameters The moments of the prior and posterior distribution for each parameter that we estimate are reported in Table $1 .{ }^{18}$ We use the same prior distributions for parameters common to both countries. The prior of our key parameter, $\tau$, the trade elasticity of substitution is centered at 1 , and allows for a wide range of possible outcomes for the sign and magitude of spillovers of US monetary policy to Canada. We also use loose priors over the slopes of the price equations, which translates into a wide range of possible degrees of price stickiness in both the US and Canada. Our priors over the annual trend growth rate and the targeted annual inflation rates in both the US and Canada are centered at $2 \%$, while the 10 th and 90 th percentiles of the prior distributions over these parameters are $1.2 \%$ and $2.8 \%$ respectively.

The monetary policy feedback rules respond to the growth rate of GDP and to the

\footnotetext{
${ }^{17}$ As an example, in the May 2013 press release, the Bank of Canada said that 'With continued slack in the Canadian economy, the muted outlook for inflation, and the constructive evolution of imbalances in the household sector, the considerable monetary policy stimulus currently in place will likely remain appropriate for a period of time, after which some modest withdrawal will likely be required, consistent with achieving the 2 per cent inflation target.'

${ }^{18} \mathrm{We}$ plot in the Appendix prior and posterior distributions for the structural parameters.
} 
detrended level of output, given the Fed's emphasis on the subdued labor market outcomes over the 2009-2015 period. We put loose priors over the coefficients on these variables. The estimates of the monetary policy rule will be important for accurately estimating anticipated forward guidance durations, as it is the monetary policy regime that the economy reverts to following a period of time at a fixed interest rate which is important for governing expectations about the path of the interest rate, and therefore in determining the stimulatory effect of forward guidance. Finally, we use wide priors for the standard deviations of the autoregressive shocks for both the US and Canada.

The estimated parameters of the monetary policy rules are similar for the two economies. We estimate the slope of the log-linearized Phillips curves, which we denote by $\kappa^{*}, \kappa, \kappa_{x}$ and $\kappa_{m}$, rather than the Calvo parameters directly. ${ }^{19}$ The slopes of the domestic and foreign Phillips curves are estimated to be quite small, and therefore imply quite sticky prices, in line with the estimates of del Negro et al. (2015), and others. The slopes of the Phillips curves for import and export prices are steeper than those of domestic prices, as in Justiniano and Preston (2010).

The posterior estimate of the trade elasticity, $\tau$, is centered around 1.27, which is above the estimate for Canada obtained by Justiniano and Preston (2010) of about 0.8, but similar to those reported in other estimated small open economy models. ${ }^{20}$ As discussed above, this parameter governs the response of domestic output to foreign monetary policy disturbances. We thus describe in more detail how it is identified in estimation.

The trade elasticity governs how much domestic output responds to changes in relative prices between the domestic and foreign economy. A lower trade elasticity makes domestic output less responsive to changes in relative prices. Less responsive output implies smaller changes in labor demand which in turn imply smaller changes in marginal cost and inflation. Through the policy rule this means the nominal interest rate is also less responsive. Following an expansionary monetary policy abroad, the interest rate differential between foreign and domestic interest rates would be larger the lower the trade elasticity. Through uncovered interest rate parity, this implies larger changes of the nominal exchange rate.

The estimation procedure chooses a value of $\tau$ that helps the model to jointly match the behaviour of domestic output and the nominal exchange rate. While a lower value of $\tau$ would imply that expansionary monetary policy in the US is also expansionary for Canada, a lower value of $\tau$ also reduces the variance of domestic output and increases the variance of the

\footnotetext{
${ }^{19}$ For example, $\kappa^{*}=\left(1-\theta^{*}\right)\left(1-\beta \theta^{*}\right) / \theta^{*}$.

${ }^{20}$ For example for Sweden, Adolfson et al. (2013) report an estimate of 1.41.
} 
nominal exchange rate. In fact, we estimated a specification in which $\tau$ is constrained to $1 / 3$ and found that larger shocks were required to explain the nominal exchange rate.

In Figure 4, we compare the responses on impact of Canadian output to an expansionary US monetary policy shock at different values of $\tau$, the trade elasticity. We draw parameters from the prior and posterior distributions and solve the model for each draw. Figure 4 illustrates that our priors are wide enough to allow an expansionary US monetary policy shock to be expansionary or contractionary for Canadian output. For the entire posterior distribution, however, we find that the output responses are negative.

Turning to the estimates of the shock processes, relative to the priors, the data prefer persistent demand shocks in the US, and relatively less persistent TFP shocks in Canada, consistent with the relative differences in persistence found in Kulish and Rees (2011). For both economies, demand shocks are more persistent and the standard deviation of demand shocks are estimated to be roughly four times as large than technology shocks, in line with the relative sizes of comparable shocks found in Ireland (2004) and Kulish and Rees (2011). To understand the implications of these parameter estimates, we report in Table 2 the forecast error variance decomposition of both US and Canadian variables into the structural shocks of the model. ${ }^{21}$ US preference shocks account for about $90 \%$ of the variation in detrended US output in the long run, and $75 \%$ of the variation in the Fed Funds rate. Consistent with the findings of Smets and Wouters (2007), US monetary policy shocks drive a small percentage of US output and inflation. US preference shocks account for about $5 \%$ of the forecast error of Canadian output, while US monetary policy shocks account for little of the long-run variation in Canadian output. Instead, about $70 \%$ of the variation in Canadian output is driven by Canadian preference shocks. Risk premia shocks are important for Canadian business cycles, accounting for about $23 \%$ of the forecast error of output.

Expected Durations For the sequence of US expected durations, we use an informative prior as in Kulish, Morley and Robinson (2017), using survey data from Blue Chip from 2009 to 2010, and survey data from the NY Fed from 2011 to 2015. For Canada we use an uninformative prior as equivalent survey measures are not available. ${ }^{22}$ The posterior distributions for the anticipated durations of the US Fed Funds rate at $0.125 \%$ between 2009Q1 and 2014Q4, and the Bank of Canada's Bank Rate at 0.25\% between 2009Q2 and 2010 Q2 and 1\% between 2010Q3 and 2014Q4 are in Table 3.

\footnotetext{
${ }^{21}$ The shocks to the $2 \mathrm{Y}$ yields capture only deviations of the $2 \mathrm{Y}$ interest rates from the expectations hypothesis, and so do not affect the model's other variables.

${ }^{22}$ The priors and posterior distributions for the sequence of expected durations are plotted in the Appendix.
} 
The posteriors show that the expected durations are well identified. For the US, the central value of each posterior density lies between 3 and 10 quarters. The posterior densities noticeably shift towards longer durations in 2011Q2, with the mean of the posteriors increasing from 5 quarters in 2011Q1 to 8.5 quarters in 2011Q2, and staying around 8 quarters until the start of 2014Q1, after which the mean of the posteriors declines to around 6 quarters. These values are consistent with the results of Swanson and Williams (2014), who find expected durations of around 7 quarters for each quarter from 2011, and aligns with the explicit adoption of forward guidance from 2011Q3, when the Federal Reserve announced that it would maintain the interest rate at $0.125 \%$ until mid-2013. Subsequently, the Fed repeatedly extended the explicit liftoff date back, which is consistent with our estimated posterior distributions remaining centered around 6 to 7 quarters.

For Canada, the estimated posterior distributions are centered around lower fixed interest rate durations, with mean durations of between 3 and 7 quarters over the estimation sample. The mass of the posterior distribution of the fixed interest rate regimes shrinks towards smaller durations for the first three quarters that the Canadian Bank Rate is fixed at 0.25\% in 2009, which is consistent with the Bank of Canada raising its policy interest rate to $1 \%$ in third quarter of 2010, and keeping it fixed thereafter.

\section{Spillovers of US Monetary Policy}

We next use the estimated model to study the spillovers of US monetary policy shocks on Canada. We first use our solution methods to measure forward guidance shocks in each country. We then compare the size and magnitude of the spillovers of conventional US monetary policy shocks when interest rates in the US and Canada follow a reaction function, to the spillovers that arise in response to a typical US forward guidance shock. Next, we show that the extent of these spillovers depends on the state of the US economy. Finally, we compute counterfactuals and use the model to quantify the spillovers from US forward guidance shocks between 2009 and 2014.

\subsection{Identified Forward Guidance in the US and Canada}

We first report our estimated measure of forward guidance in the US and Canada. To measure forward guidance, we repeatedly draw from the posterior distribution of parameters and durations. For each draw, we use the observables and the Kalman smoother to estimate the model's structural shocks. We then follow the methods discussed in Section 3 and use the 
structural shocks to identify the fixed interest rate durations which are consistent with the estimated structural shocks, which we define as the sequence of endogenous durations for each country. Forward guidance is then the difference between the fixed interest rate durations consistent with the data, and the endogenous durations, at each quarter. Forward guidance shocks are unexpected changes in the forward guidance component of the total duration.

Figure 6 plots the mean of the set of draws of fixed interest rate durations and endogenous durations for the US and Canada. For the US, the mean across durations is initially around 4 quarters to 6 quarters, from 2009 to early 2011 (see also Table 3), of which the mean across endogenous durations is roughly half the total duration, between 2 quarters and 3 quarters. We estimate therefore that US forward guidance was responsible for about half of the expected duration of fixed interest rate policy between 2009 and 2011, or between 2 quarters and 3 quarters in duration.

From early to mid-2011, to late 2013, we find that forward guidance shocks in the US expanded markedly. Following the Fed's explicit calendar-based commitment to holding the Fed Funds rate fixed from early to mid-2011, we estimate that the endogenous durations stayed roughly constant, between 2 quarters and 4 quarters, so that the forward guidance announcements were about 4 quarters to 5 quarters. As discussed below in the counterfactual simulations, we find that these announcements were stimulatory for the US and, owing to the estimated elastic demand by the US for Canadian exports, were contractionary in Canada.

In Panel B of Figure 6, we plot the corresponding decomposition of the estimated total expected durations of fixed interest rate policy in Canada. ${ }^{23}$ The estimated endogenous duration is roughly constant over the 2009Q2 to 2014Q4 period, mostly being between 2 quarters and 4 quarters in duration.

\subsection{Conventional and Unconventional Shocks}

The non-linearity of the solution during the period of fixed interest rates, as we showed above, implies a time-varying VAR of the form $x_{t}=\mathbf{J}_{t}+\mathbf{Q}_{t} x_{t-1}+\mathbf{G}_{t} \varepsilon_{t}$. A forward guidance shock is a change to $\mathbf{Q}_{t}$ and so its impact depends on the state of the economy $x_{t-1}$. We will explore the state dependence in the next section, but to get a sense of the possible magnitudes and dynamics involved, we first compare impulse responses to a conventional shock with those to a forward guidance shock. We do so at the mode of the estimated values of the parameters and for illustration, we consider a 2 quarter forward guidance shock in 2012Q1. The forward

\footnotetext{
${ }^{23}$ Recall, these durations are for fixed interest rate policy at $0.25 \%$ between 2009 Q2 and 2010Q1, and then at $1 \%$ from $2010 \mathrm{Q} 2$ to $2014 \mathrm{Q} 4$, the end of the sample.
} 
guidance shock amounts to an extension of 2 quarters to the estimated duration, which at the median draw is 7 quarters. We choose 2 quarters because it is the mean across the sample for forward guidance shocks in the US.

Figure 7 compares impulse responses of a one standard deviation conventional expansionary monetary policy (about 50 annual basis points) with the impulse response to a 2 quarter forward guidance shock. For the forward guidance shock we use generalized impulse responses following Koop et al. (1996). These are computed as the difference between the forecast paths of variables with and without the forward guidance shock. This explains why an expansionary forward guidance shock implies a fall of the interest rate by the time of liftoff under the estimated duration, because the interest rate under the forward guidance shock remains lower under the fixed interest rate extension. A forward guidance shock therefore only affects the expect path of the Federal Funds rate but has no impact on its contemporaneous value.

A forward guidance shock implies the same qualitative responses as a conventional shock. An expansionary forward guidance shock increases output and inflation in the US and appreciates the Canadian real exchange rate which leads to a decrease in domestic output and inflation in Canada. At the modal draw notice that a forward guidance shock implies responses which are between 2 or 3 times larger than a conventional shock and, in the case of output responses, are more persistent.

\subsection{State Dependence of Forward Guidance Shocks}

The state of the US preference shock, $\xi_{t}^{*}$, can amplify or diminish the impact of a forward guidance shock. To see this, take the demand equation for the US, which is the only equation apart from the foreign interest rate rule where $r_{t}^{*}$ enters, and set for simplicity the habits parameter to zero:

$$
y_{t}^{*}=\mathbb{E}_{t} y_{t+1}^{*}-\left(r_{t}^{*}-\mathbb{E}_{t} \pi_{t+1}^{*}-\left(1-\rho_{\xi}^{*}\right) \xi_{t}^{*}\right)
$$

Iterating this equation forward reveals that it is the expected path of the last term on the right hand side, $r_{t}^{*}-\mathbb{E}_{t} \pi_{t+1}^{*}-\left(1-\rho_{\xi}^{*}\right) \xi_{t}^{*}$, that matters for output. The expression makes clear why the impact of the expected duration depends on the nature of the risk premium shock. A large, negative and persistent $\xi_{t}^{*}$ offsets any potentially expansionary impact of the expected duration. Conversely, a small, positive and persistent $\xi_{t}^{*}$ can in fact amplify the expansionary impact of the expected duration. This also explains why one may find large estimates of the expected duration which do not give rise to implausibly large responses of aggregate variables, counter to the 'forward guidance puzzle' phenomenon identified by Carlstrom et al. (2015) and del Negro et al. (2012). Thus, an extension of the expected duration that lowers the 
expected path of $r_{t}^{*}$ will have a smaller impact on output, the more negative and persistent is the foreign preference shock, $\xi_{t}^{*}$.

Figure 8 plots the impulse responses for the US and Canada to an extension of the forward guidance component of the duration of 2 quarters for two sets of different draws. In one case, we take draws for which the standard deviation of the US preference shock, $\xi_{t}^{*}$, is smaller than 0.35. And in the other case, we take draws for which the standard deviation of the US preference shock, $\xi_{t}^{*}$, is higher than $0.55 .^{24}$ We further condition on draws for which the duration in $2012 \mathrm{Q} 1$ is 8 quarters.

For each draw we obtained smoothed estimates of the shocks and states and use these to compute generalized impulse responses for output, inflation and the real exchange rate. A 2 quarter forward guidance shock in the US leads to mild spillovers on Canadian output $(-0.06 \%$ at mean $)$ when the state of the US preference shock is very negative. On the other hand, when the state of the US preference shock is benign, the spillovers from US forward guidance can be up to four times as large $(-0.2 \%$ at the mean). We plot the mean of the impulse responses for all draws together with 50 other draws chosen at random, to illustrate the dispersion of the spillovers of forward guidance.

\subsection{Counterfactual Scenarios}

Next, we use the estimated model to construct a counterfactual in which we remove forward guidance in both the US and Canada, and a counterfactual in which we remove forward guidance in the US alone. In Figure 9, we plot the change in output in the counterfactual from that observed, for the US and Canada. We find that, absent forward guidance in the US and Canada, the cumulative decline in output would be about $27 \%$, suggesting that forward guidance was stimulatory, particularly between 2011 and 2014. Forward guidance in Canada was also stimulatory. We find that removing forward guidance in Canada and in the US would reduce Canadian output by almost $15 \%$ in cumulative terms, with the deepest counterfactual declines occurring between 2010 and 2012.

Our second counterfactual explores the consequences of removing US forward guidance only, but keeping Canadian forward guidance. To construct this counterfactual, we do not allow the US to announce an extension of the fixed interest rate policy beyond the durations implied by a lower bound constraint. In response, we keep the expected fixed interest rate durations in Canada at their posterior medians. We plot the change in output in Figure 10. First, as one would expect, the decline in US output in Panel A is the same as the decline in

\footnotetext{
${ }^{24}$ The mode of the standard deviation of $\xi_{t}^{*}$ is 0.42 .
} 
the counterfactual removing forward guidance in both countries. However, the experience of Canada is different. Instead, between 2011 and 2014, output in Canada is higher, with output being, cumulatively, almost $4 \%$ higher when US forward guidance shocks are removed. This is a direct measure of the spillovers of US forward guidance, and shows that forward guidance announcements by the Bank of Canada helped to mitigate the contractionary effects of expansionary US monetary policy.

\section{Conclusions}

In this paper, we examine empirically how forward guidance of the US Fed Funds rate at its lower bound affects monetary policy and economic dynamics in Canada, a small open economy. To this end, we estimate a two-country small open economy model on US and Canadian data accounting for fixed interest rates from 2009Q1 onwards. In estimating these durations we allow, but do not require, that the durations be those that arise if we were to treat the level of the fixed interest rate as an occasionally binding lower bound constraint. This is important given the optimal policy prescription of prolonging the duration of the fixed interest rate period to alleaviate the contractionary impact of the constraints.

We estimate anticipated fixed interest rate durations of around 4 to 9 quarters, of which roughly half in the US are explained by shocks to the economy between 2009 and 2011, with the fraction explained by forward guidance increasing to about two-thirds between 2011 and 2014. About half of the Canadian durations we find to be due to deliberate forward guidance. Our results suggest that both countries made use of forward guidance successfully to stimulate output and inflation. In counterfactual simulations, we find that if neither country used the expectations channel of policy, output and inflation in both countries would have been substantially lower. We also find that if the US did not use forward guidance, but the expected durations of fixed interest rates were unchanged in Canada, that Canadian output would have been, cumulatively, $4 \%$ higher. We therefore identify notable spillovers of US forward guidance policy on Canada and find expansionary US forward guidance to be contractionary for Canada, but that US and Canadian forward guidance were stabilizing on the whole. 


\section{References}

Adolfson, Malin, Stefan Laseen, Lawrence Christiano, Mathias Trabandt, and Karl Walentin, "Ramses II - Model Description," Occasional Paper 12, Sveriges Riksbank 2013.

Ammer, John, Michiel De Pooter, Christopher J Erceg, Steven B Kamin et al., "International spillovers of monetary policy," Technical Report, Board of Governors of the Federal Reserve System (US) 2016.

Anaya, Pablo, Michael Hachula, and Christian J Offermanns, "Spillovers of US unconventional monetary policy to emerging markets: The role of capital flows," Journal of International Money and Finance, 2017, 73, 275-295.

Bernanke, Ben S, "Federal reserve policy in an international context," IMF Economic Review, 2017, 65 (1), 5-36.

- and Vincent $\mathbf{R}$ Reinhart, "Conducting monetary policy at very low short-term interest rates," The American Economic Review, 2004, 94 (2), 85-90.

Bodenstein, Martin, Christopher J Erceg, and Luca Guerrieri, "The effects of foreign shocks when interest rates are at zero," Canadian Journal of Economics/Revue canadienne d'économique, 2017, 50 (3), 660-684.

Burgess, Stephen, Emilio Fernandez-Corugedo, Charlotta Groth, Richard Harrison, Francesca Monti, Konstantinos Theodoridis, and Matt Waldron, "The Bank of England's forecasting platform: COMPASS, MAPS, EASE and the suite of models," Working Paper 471, Bank of England 2013.

Cagliarini, Adam and Mariano Kulish, "Solving Linear Rational Expectations Models with Predictable Structural Changes," Review of Economics and Statistics, March 2013, 95 (1), 328-336.

Campbell, Jeffrey R., Charles L. Evans, Jonas D.M. Fisher, Alejandro Justiniano, Charles W. Calomiris, and Michael Woodford, "Macroeconomic Effects of Federal Reserve Forward Guidance," Brookings Papers on Economic Activity, 2012, Spring, 1-80.

Carlstrom, Charles T, Timothy S Fuerst, and Matthias Paustian, "Inflation and output in New Keynesian models with a transient interest rate peg," Journal of Monetary Economics, 2015, 76, 230-243.

Chen, Jiaqian, Tommaso Mancini Griffoli, and Ratna Sahay, "Spillovers from United States Monetary Policy on Emerging Markets: Different This Time?," Working Paper 14-240, IMF 2014.

Chen, Qianying, Andrew Filardo, Dong He, and Feng Zhu, "Financial crisis, US unconventional monetary policy and international spillovers," Journal of International Money and Finance, 2016, 67, 62-81.

Cochrane, John H, "Monetary policy with interest on reserves," Journal of Economic Dynamics and Control, 2014, 49, 74-108. 
De Paoli, Bianca, "Monetary Policy and Welfare in a Small Open Economy," Journal of International Economics, 2009, 77 (1), 11 - 22.

Dedola, Luca, Giulia Rivolta, and Livio Stracca, "If the Fed sneezes, who catches a cold?," Journal of International Economics, 2017, 108, S23-S41.

del Negro, Marco, Marc Giannoni, and Christina Patterson, "The Forward Guidance Puzzle," Staff Reports 574, Federal Reserve Bank of New York 2012.

_, Marc P Giannoni, and Frank Schorfheide, "Inflation in the Great Recession and New Keynesian Models," American Economic Journal: Macroeconomics, 2015, 7 (1), $168-196$.

Eggertsson, Gauti B and Michael Woodford, "The Zero Bound on Interest Rates and Optimal Monetary Policy," Brookings Papers on Economic Activity, 2003, 1, 139-233.

Eichengreen, Barry and Jeffrey Sachs, "Exchange Rates and Economic Recovery in the 1930s," The Journal of Economic History, 1985, 45 (4), 925-946.

Fujiwara, Ippei, Tomoyuki Nakajima, Nao Sudo, and Yuki Teranishi, "Global Liquidty Trap," Journal of Monetary Economics, 2013, 60 (8), 936-949.

Galí, Jordi and Tommaso Monacelli, "Monetary Policy and Exchange Rate Volatility in a Small Open Economy," Review of Economic Studies, 2005, 72, 707-734.

Graeve, Ferre De, Marina Emiris, and Raf Wouters, "A Structural Decomposition of the US Yield Curve," Journal of Monetary Economics, 2009, 56, 545-559.

Guerrieri, Luca and Mateo Iacoviello, "OccBin: A toolkit for solving dynamic models with occasionally binding constraints easily," Journal of Monetary Economics, 2015, 70, $22-38$.

Haberis, Alex and Anna Lipinska, "International Policy Spillovers at the Zero Lower Bound," Technical Report 2012.

Ireland, Peter, "Technology Shocks in the New Keynesian Model," Review of Economics and Statistics, November 2004, 86 (4), 923-936.

Jones, Callum, "Unanticipated Shocks and Forward Guidance at the Zero Lower Bound," 2017.

_ , Virgiliu Midrigan, and Thomas Philippon, "Household Leverage and the Recession," mimeo 2017.

Justiniano, Alejandro and Bruce Preston, "Monetary Policy and Uncertainty in an Empirical Small Open Economy Model," Journal of Applied Econometrics, 2010, 25 (1), 93-128.

Kim, Soyoung, "International transmission of US monetary policy shocks: Evidence from VAR's," Journal of Monetary Economics, 2001, 48 (2), 339-372. 
Koop, Gary, M. Hashem Pesaran, and Simon M. Potter, "Impulse response analysis in nonlinear multivariate models," Journal of Econometrics, September 1996, 74 (1), 119-147.

Kulish, Mariano and Adrian Pagan, "Estimation and solution of models with expectations and structural changes," Journal of Applied Econometrics, 2017, 32 (2), 255-274.

- and Daniel Rees, "The Yield Curve in a Small Open Economy," Journal of International Economics, 2011, 85 (2), 268-279.

_, James Morley, and Tim Robinson, "Estimating DSGE models with zero interest rate policy," Journal of Monetary Economics, 2017, 88, 35-49.

Leeper, Eric M, "Equilibria Under 'Active' and 'Passive' Monetary and Fiscal Policies," Journal of Monetary Economics, 1991, 27 (1), 129-147.

Mundell, Robert A., International Economics, MacMillan, 1968.

Murray, J, "Exits, Spillovers and Monetary Policy Independence," Speech to the Canadian Association for Business Economics, Kingston, Ontario, 2013, 27.

Paoli, Bianca De, "Monetary policy under alternative asset market structures: The case of a small open economy," Journal of Money, Credit and Banking, 2009, 41 (7), 1301-1330.

Rajan, Raghuram, "Competitive monetary easing: is it yesterday once more?," Macroeconomics and Finance in Emerging Market Economies, 2015, 8 (1-2), 5-16.

Smets, Frank and Rafael Wouters, "Shocks and Frictions in US Business Cycles: A Bayesian DSGE Approach," American Economic Review, 2007, 96 (3), 586-606.

Swanson, Eric T. and John C. Williams, "Measuring the Effect of the Zero Lower Bound on Medium- and Longer-Term Interest Rates," American Economic Review, 2014, 104 (10), 3154-3185.

Tillmann, Peter, "Unconventional monetary policy and the spillovers to emerging markets," Journal of International Money and Finance, 2016, 66, 136-156. 
Table 1: Estimated Parameters

\begin{tabular}{|c|c|c|c|c|c|c|c|c|}
\hline \multirow[b]{2}{*}{ Parameter } & \multicolumn{4}{|c|}{ Prior } & \multicolumn{4}{|c|}{ Posterior } \\
\hline & Dist & Median & $10 \%$ & $90 \%$ & Mode & Median & $10 \%$ & $90 \%$ \\
\hline \multicolumn{9}{|c|}{ A. Structural Parameters } \\
\hline$\tau$ & G & 1.0 & 0.5 & 3.3 & 1.27 & 1.31 & 1.12 & 1.52 \\
\hline $100 \times \kappa^{*}$ & $\mathrm{G}$ & 5.0 & 3.0 & 10.0 & 0.10 & 0.12 & 0.07 & 0.18 \\
\hline $100 \times \kappa$ & G & 5.0 & 3.0 & 10.0 & 0.31 & 0.32 & 0.24 & 0.43 \\
\hline $100 \times \kappa_{x}$ & G & 10.0 & 3.0 & 20.1 & 1.56 & 1.80 & 1.16 & 2.73 \\
\hline$\kappa_{m}$ & $\mathrm{~N}$ & 1.0 & 0.8 & 1.2 & 0.77 & 0.78 & 0.56 & 1.00 \\
\hline $100 \times(\mu-1)$ & $\mathrm{N}$ & 0.5 & 0.3 & 0.7 & 0.47 & 0.47 & 0.44 & 0.50 \\
\hline $100 \times\left(\pi^{*}-1\right)$ & $\mathrm{N}$ & 0.5 & 0.3 & 0.7 & 0.50 & 0.49 & 0.39 & 0.58 \\
\hline $100 \times(\pi-1)$ & $\mathrm{N}$ & 0.5 & 0.3 & 0.7 & 0.63 & 0.63 & 0.55 & 0.70 \\
\hline$\rho_{r}^{*}$ & B & 0.7 & 0.6 & 0.9 & 0.88 & 0.88 & 0.85 & 0.90 \\
\hline$\phi_{\pi}^{*}$ & $\mathrm{~N}$ & 2.0 & 1.8 & 2.2 & 1.98 & 1.96 & 1.78 & 2.14 \\
\hline$\phi_{g}^{*}$ & $\mathrm{~N}$ & 0.2 & 0.1 & 0.3 & 0.30 & 0.30 & 0.19 & 0.41 \\
\hline$\phi_{y}^{*}$ & G & 0.2 & 0.1 & 0.3 & 0.11 & 0.12 & 0.07 & 0.17 \\
\hline$\rho_{r}$ & B & 0.7 & 0.6 & 0.9 & 0.85 & 0.85 & 0.82 & 0.87 \\
\hline$\phi_{\pi}$ & $\mathrm{N}$ & 2.0 & 1.8 & 2.2 & 1.95 & 1.94 & 1.76 & 2.14 \\
\hline$\phi_{g}$ & $\mathrm{~N}$ & 0.2 & 0.1 & 0.3 & 0.29 & 0.28 & 0.16 & 0.39 \\
\hline$\phi_{y}$ & G & 0.2 & 0.1 & 0.4 & 0.12 & 0.13 & 0.10 & 0.16 \\
\hline \multicolumn{9}{|c|}{ B. Shock Processes } \\
\hline$\rho_{\xi}^{*}$ & B & 0.5 & 0.2 & 0.8 & 0.93 & 0.93 & 0.90 & 0.94 \\
\hline$\rho_{a}^{*}$ & $\mathrm{~B}$ & 0.5 & 0.2 & 0.8 & 0.80 & 0.79 & 0.72 & 0.85 \\
\hline $10 \times \sigma_{\xi}^{*}$ & IG & 0.6 & 0.3 & 1.8 & 0.42 & 0.43 & 0.37 & 0.49 \\
\hline $10 \times \sigma_{a}^{*}$ & IG & 0.6 & 0.3 & 1.8 & 1.04 & 1.20 & 0.73 & 2.07 \\
\hline $100 \times \sigma_{r}^{*}$ & IG & 0.6 & 0.3 & 1.8 & 0.12 & 0.12 & 0.11 & 0.14 \\
\hline$\rho_{\xi}$ & B & 0.5 & 0.2 & 0.8 & 0.91 & 0.90 & 0.88 & 0.92 \\
\hline$\rho_{a}$ & B & 0.5 & 0.2 & 0.8 & 0.38 & 0.40 & 0.28 & 0.53 \\
\hline$\rho_{p}$ & B & 0.5 & 0.2 & 0.8 & 0.97 & 0.97 & 0.96 & 0.98 \\
\hline $10 \times \sigma_{\xi}$ & $\mathrm{IG}$ & 0.6 & 0.3 & 1.8 & 0.59 & 0.60 & 0.52 & 0.69 \\
\hline $10 \times \sigma_{a}$ & IG & 0.6 & 0.3 & 1.8 & 1.74 & 2.00 & 1.48 & 2.58 \\
\hline $100 \times \sigma_{r}$ & $\mathrm{IG}$ & 0.6 & 0.3 & 1.8 & 0.19 & 0.20 & 0.18 & 0.22 \\
\hline $10 \times \sigma_{p}$ & $\mathrm{IG}$ & 1.5 & 0.7 & 3.3 & 0.52 & 0.52 & 0.46 & 0.58 \\
\hline $100 \times \sigma_{8}$ & IG & 0.1 & 0.0 & 0.2 & 0.04 & 0.06 & 0.03 & 0.12 \\
\hline $100 \times c_{8}$ & $\mathrm{~N}$ & 0.0 & -0.2 & 0.2 & -0.03 & -0.01 & -0.25 & 0.25 \\
\hline $100 \times \sigma_{8}^{*}$ & IG & 0.1 & 0.0 & 0.2 & 0.04 & 0.06 & 0.02 & 0.14 \\
\hline $100 \times c_{8}^{*}$ & $\mathrm{~N}$ & 0.0 & -0.2 & 0.2 & 0.03 & 0.03 & -0.22 & 0.30 \\
\hline
\end{tabular}


Table 2: Variance Decomposition Due to Shocks, \%

\begin{tabular}{|c|c|c|c|c|c|c|c|}
\hline \multirow[b]{2}{*}{ Variable } & \multicolumn{3}{|c|}{ US Shocks } & \multicolumn{4}{|c|}{ Canadian Shocks } \\
\hline & Preference & Productivity & Policy & Preference & Productivity & Policy & Risk Premia \\
\hline \multicolumn{8}{|c|}{ A. US Variables } \\
\hline Fed Funds Rate & 76.4 & 10.9 & 12.6 & - & - & - & - \\
\hline Inflation & 18.5 & 81.1 & 0.5 & - & - & - & - \\
\hline Output & 89.5 & 7.3 & 3.2 & - & - & - & - \\
\hline \multicolumn{8}{|c|}{ B. Canadian Variables } \\
\hline Bank Rate & 5.7 & 0.1 & 0.0 & 71.6 & 1.9 & 17.4 & 3.2 \\
\hline Inflation & 6.2 & 0.3 & 0.3 & 33.2 & 37.3 & 3.2 & 19.5 \\
\hline Output & 5.3 & 0.1 & 0.1 & 69.1 & 0.9 & 2.0 & 22.6 \\
\hline Consumption & 7.2 & 0.1 & 0.0 & 43.4 & 0.0 & 0.3 & 48.9 \\
\hline Real Exch Rate & 10.4 & 0.3 & 0.5 & 18.2 & 0.1 & 0.7 & 69.7 \\
\hline
\end{tabular}


Table 3: Posterior Distributions of ZLB Durations

\begin{tabular}{|c|c|c|c|c|c|c|c|c|}
\hline \multirow[b]{2}{*}{ Date } & \multicolumn{4}{|c|}{ US } & \multicolumn{4}{|c|}{ Canada } \\
\hline & Mean & Median & $10 \%$ & $90 \%$ & Mean & Median & $10 \%$ & $90 \%$ \\
\hline 2009Q1 & 4.8 & 4 & 1 & 10 & - & - & - & - \\
\hline 2009Q2 & 4.4 & 4 & 1 & 9 & 7.9 & 6 & 2 & 16 \\
\hline 2009Q3 & 4.1 & 4 & 2 & 7 & 5.2 & 5 & 2 & 9 \\
\hline 2009Q4 & 4.9 & 4 & 2 & 10 & 4.5 & 4 & 2 & 8 \\
\hline 2010Q1 & 3.5 & 3 & 2 & 7 & 4.5 & 3 & 1 & 9 \\
\hline 2010Q2 & 5.1 & 4 & 2 & 10 & 3.4 & 3 & 1 & 7 \\
\hline 2010Q3 & 4.3 & 4 & 2 & 7 & 5.3 & 5 & 1 & 11 \\
\hline 2010Q4 & 5.0 & 4 & 1 & 10 & 6.6 & 6 & 1 & 12 \\
\hline 2011Q1 & 5.0 & 5 & 2 & 8 & 5.6 & 5 & 1 & 11 \\
\hline 2011Q2 & 8.5 & 8 & 4 & 13 & 6.5 & 6 & 2 & 13 \\
\hline 2011Q3 & 6.7 & 7 & 2 & 11 & 6.9 & 7 & 1 & 13 \\
\hline $2011 Q 4$ & 8.4 & 9 & 4 & 12 & 6.7 & 6 & 1 & 13 \\
\hline 2012Q1 & 7.2 & 7 & 2 & 12 & 5.7 & 5 & 1 & 11 \\
\hline 2012Q2 & 7.7 & 8 & 3 & 12 & 6.3 & 5 & 1 & 13 \\
\hline 2012Q3 & 9.3 & 10 & 3 & 14 & 5.8 & 5 & 1 & 12 \\
\hline 2012Q4 & 8.3 & 9 & 3 & 13 & 6.2 & 5 & 2 & 12 \\
\hline 2013Q1 & 8.3 & 9 & 3 & 13 & 6.6 & 5 & 1 & 14 \\
\hline 2013Q2 & 6.7 & 7 & 2 & 11 & 5.8 & 5 & 1 & 11 \\
\hline 2013Q3 & 8.0 & 8 & 3 & 13 & 6.1 & 5 & 1 & 13 \\
\hline $2013 Q 4$ & 8.8 & 9 & 3 & 14 & 5.5 & 4 & 1 & 11 \\
\hline 2014Q1 & 6.3 & 6 & 3 & 9 & 7.2 & 6 & 1 & 14 \\
\hline 2014Q2 & 6.5 & 6 & 3 & 12 & 6.6 & 6 & 1 & 13 \\
\hline 2014Q3 & 5.7 & 4 & 2 & 12 & 6.0 & 5 & 1 & 12 \\
\hline 2014Q4 & 4.0 & 3 & 2 & 7 & 6.3 & 6 & 1 & 12 \\
\hline
\end{tabular}


Figure 1: Timing and Four Possible Regimes in the Model

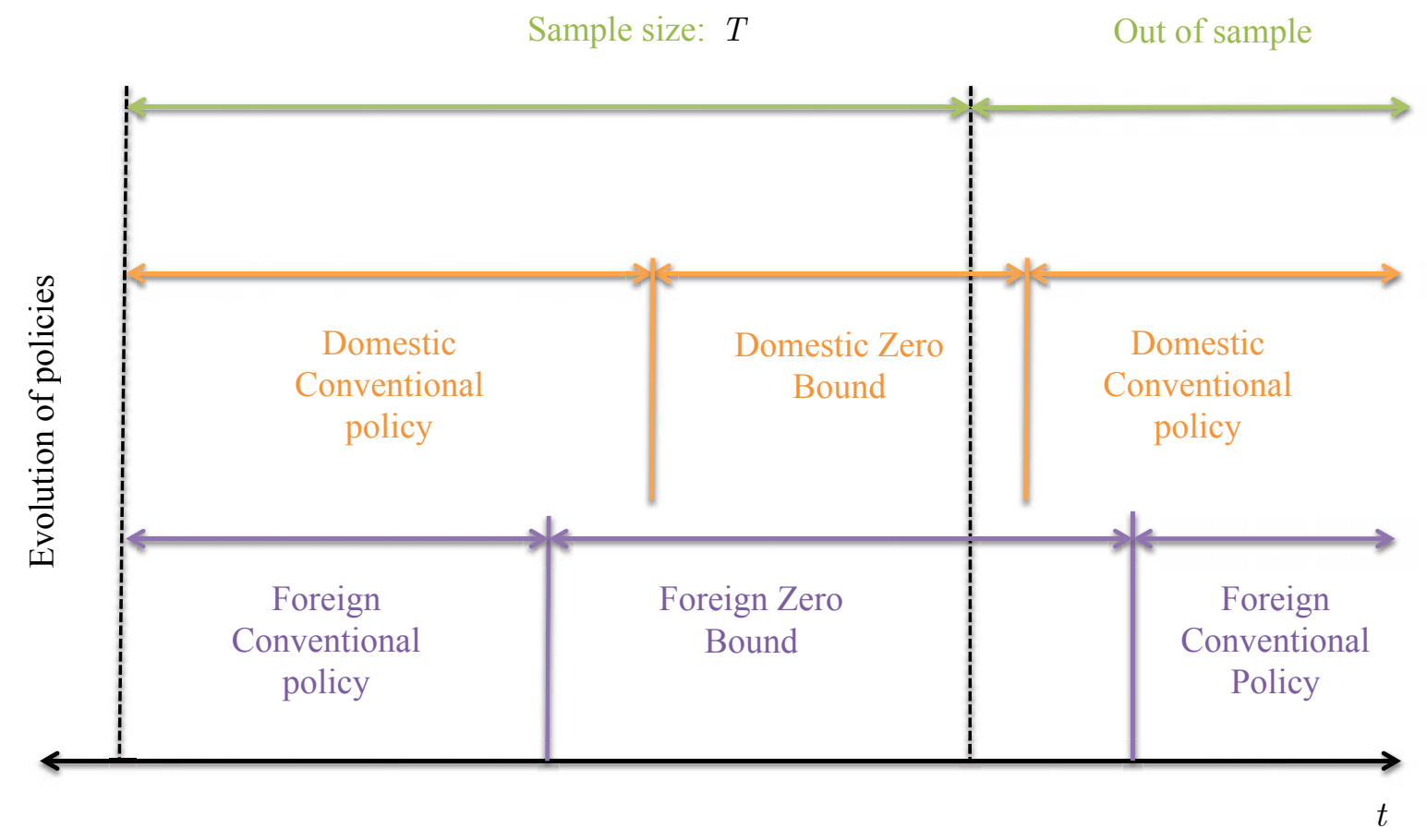


Figure 2: Example of Forward Guidance Identification

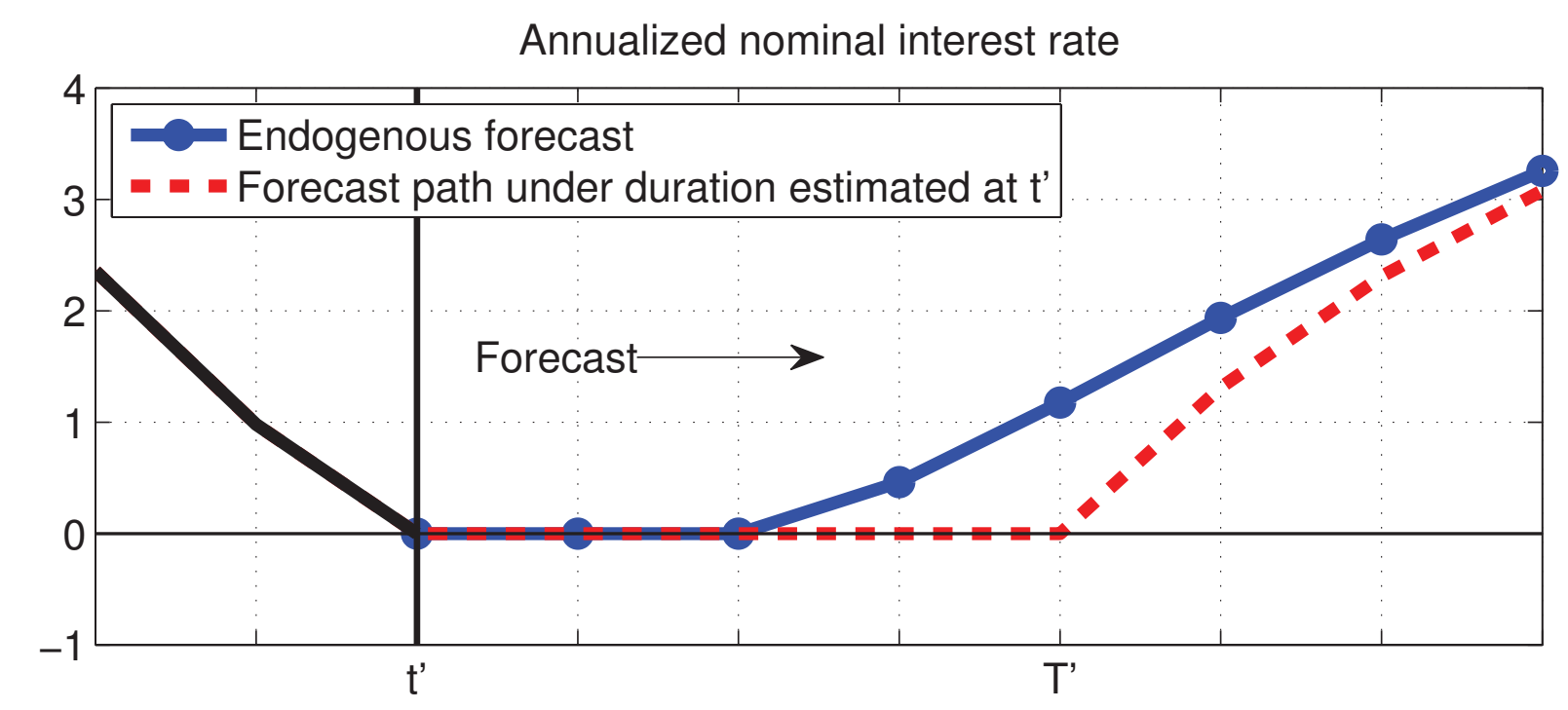

Evolution of ZLB duration estimated at t'

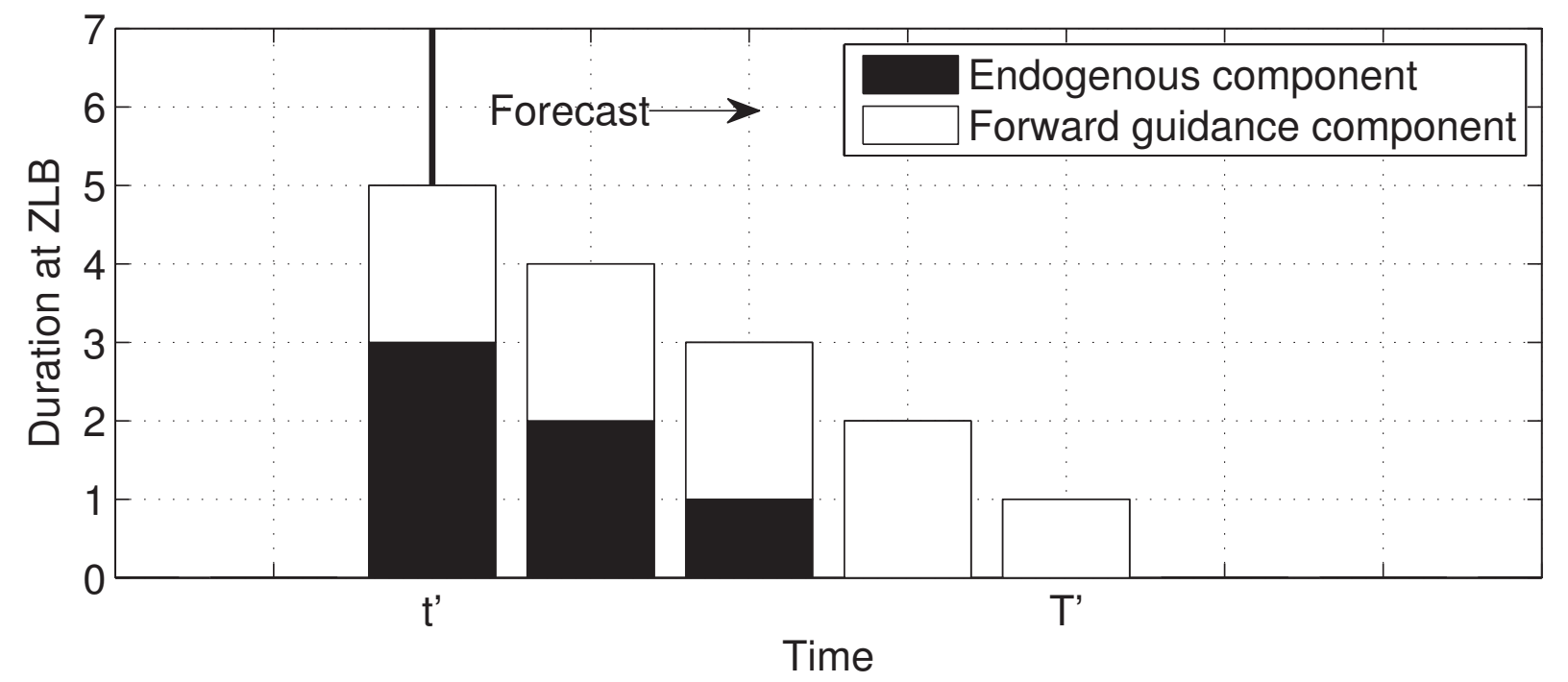


Figure 3: Quarterly Data Used in Estimation
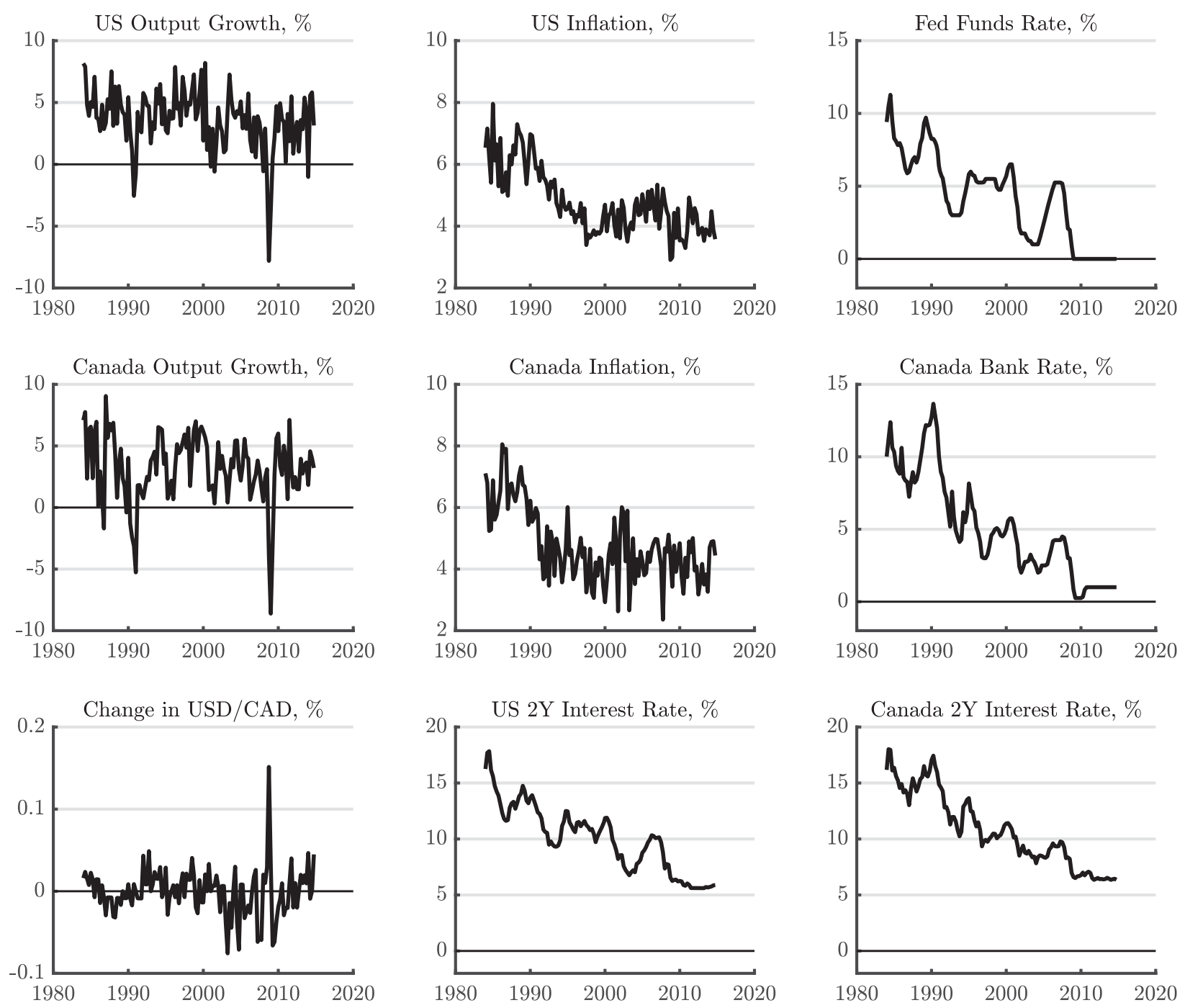
Figure 4: Canada Output Response to Expansionary US Monetary Policy Shock, \%

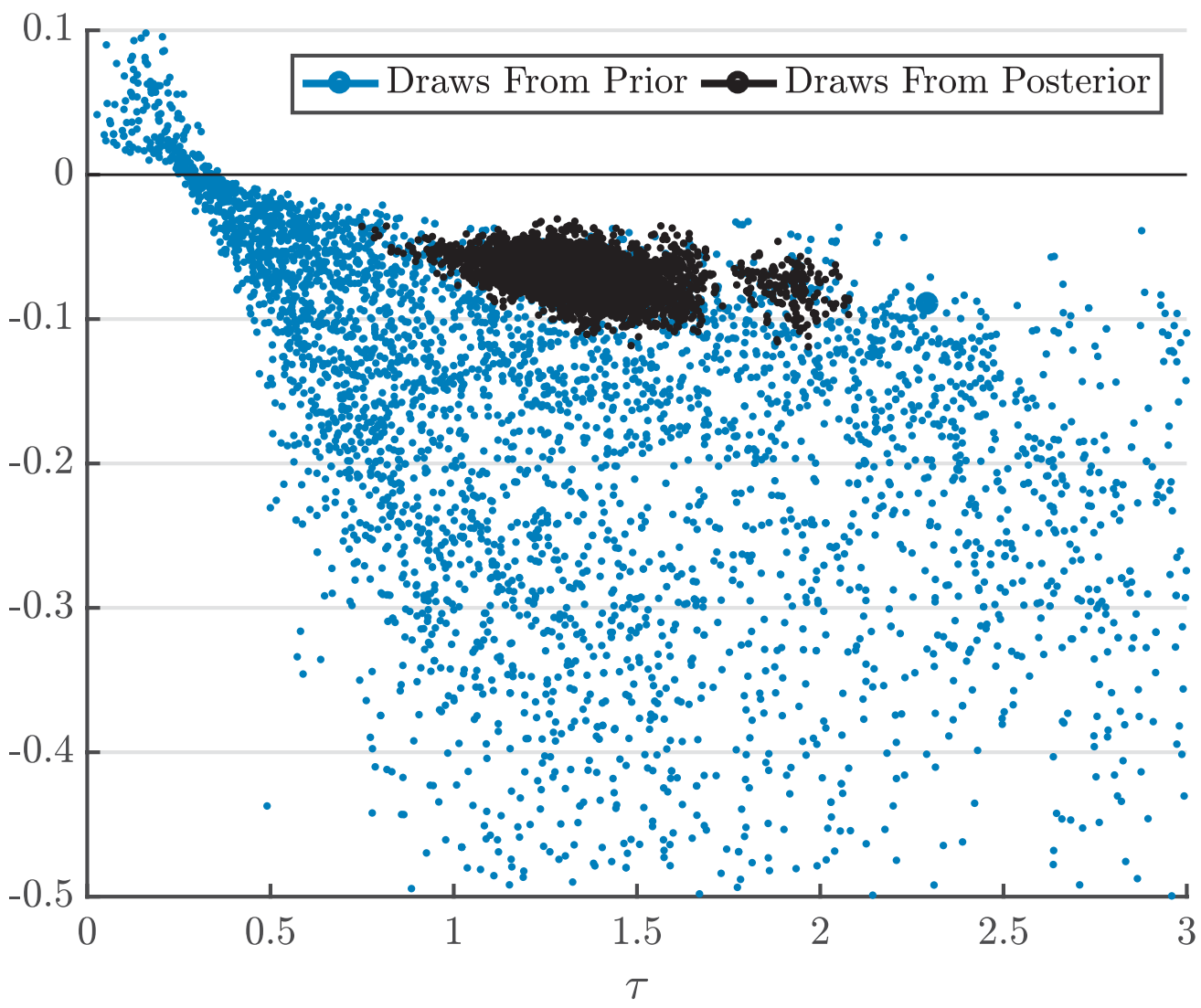


Figure 5: Impulse Response to Expansionary US Monetary Policy Shock
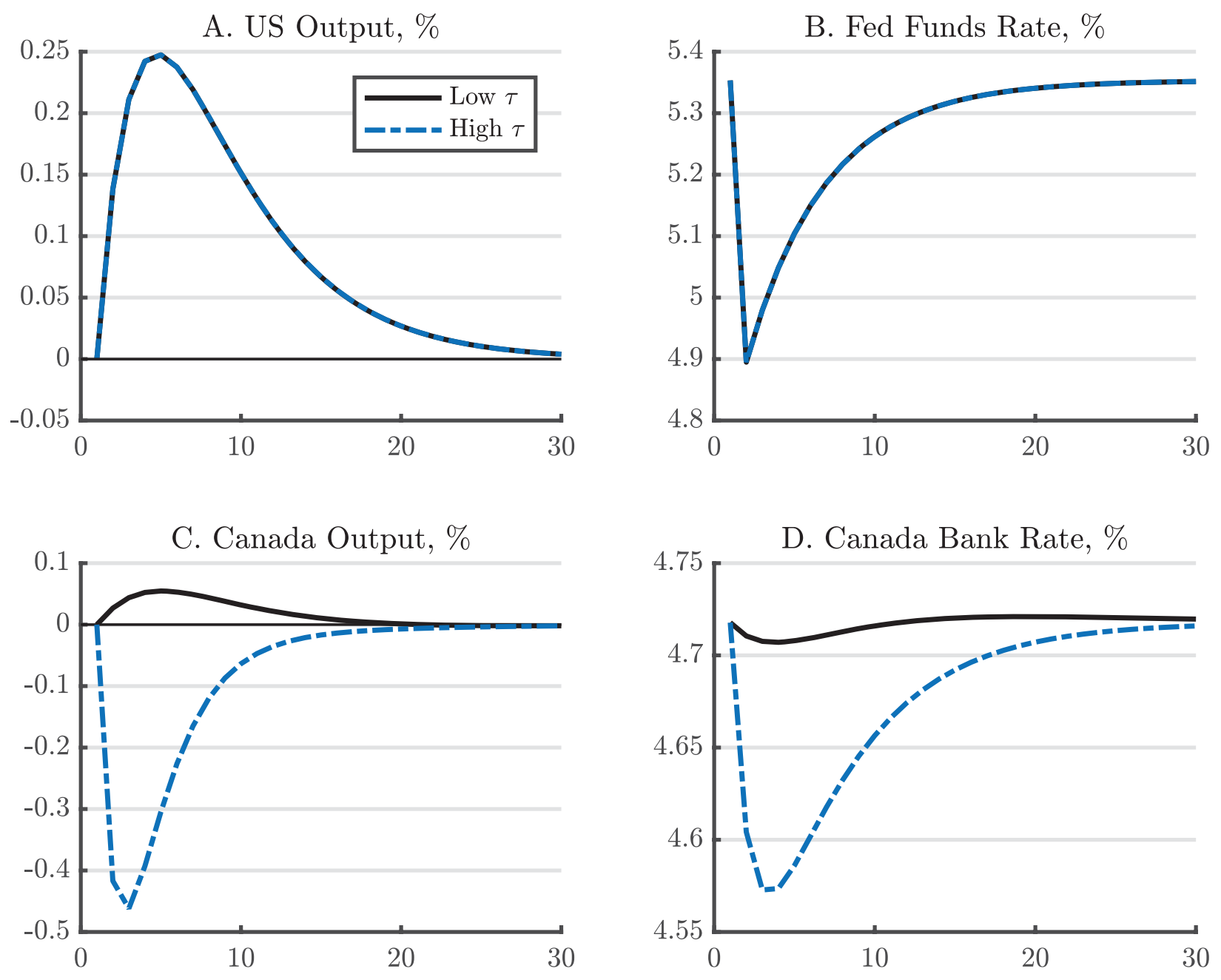
Figure 6: Fixed Interest Rate Duration and Forward Guidance, Mean Across Draws
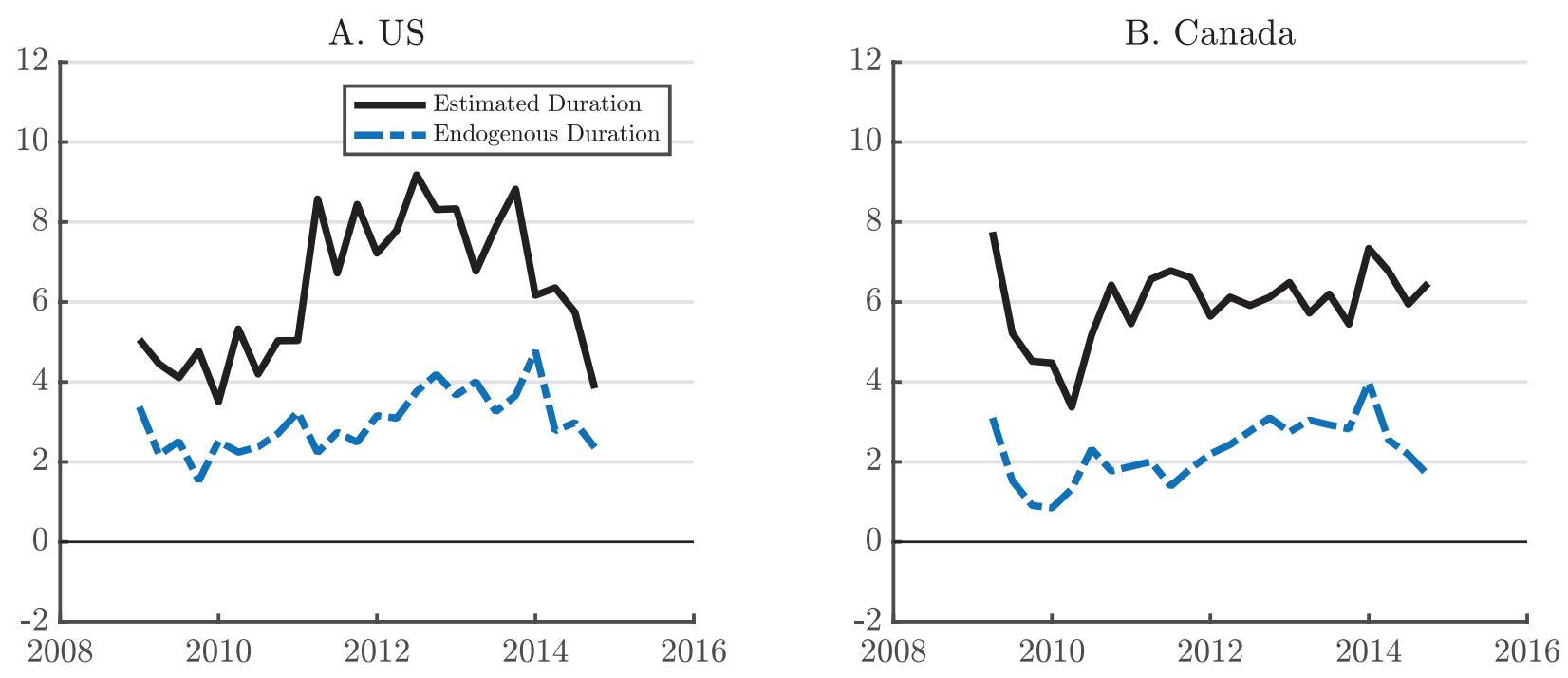
Figure 7: Comparison of Conventional US Policy Shock and US Forward Guidance Shock
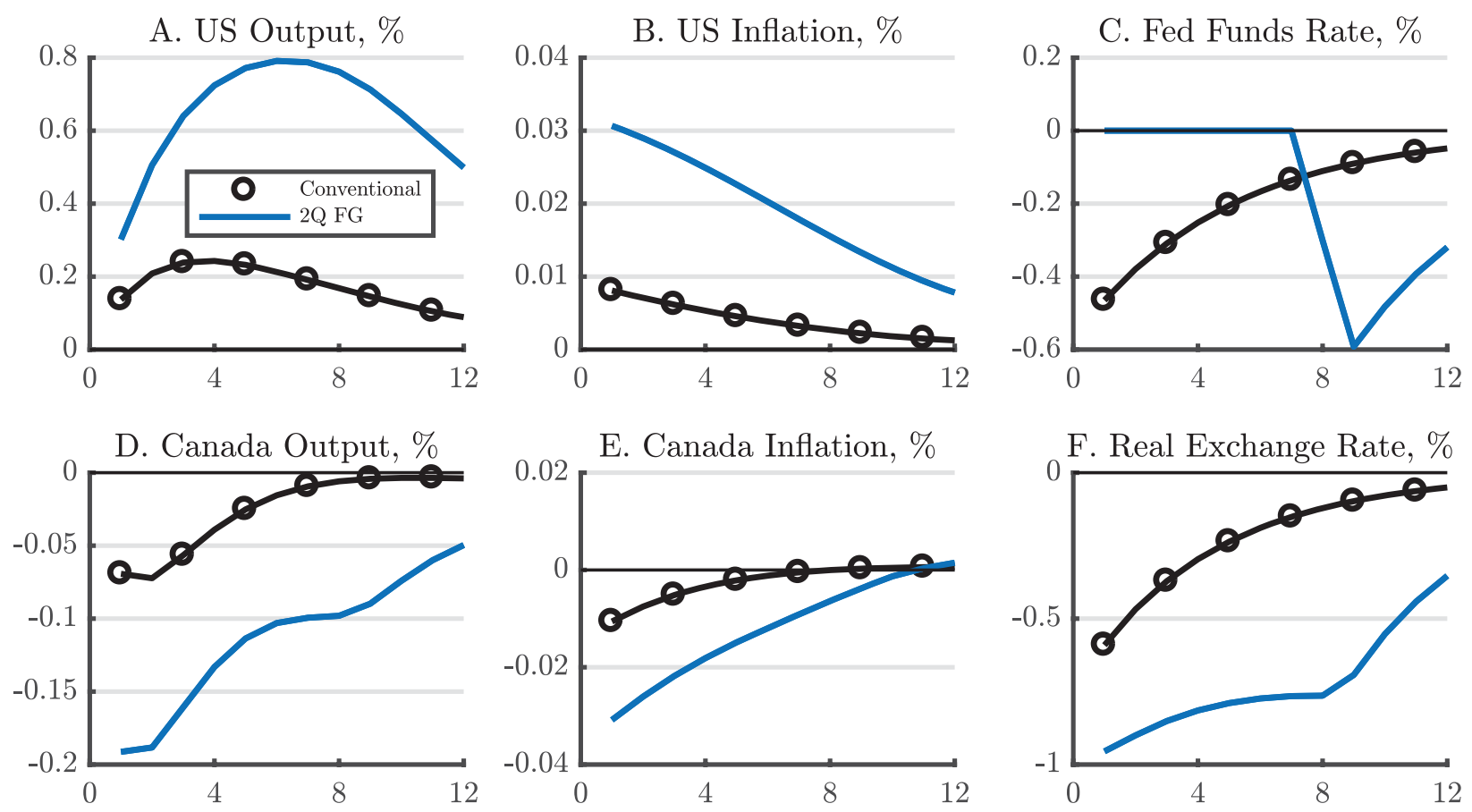
Figure 8: State Dependent Spillovers of US Forward Guidance Shock
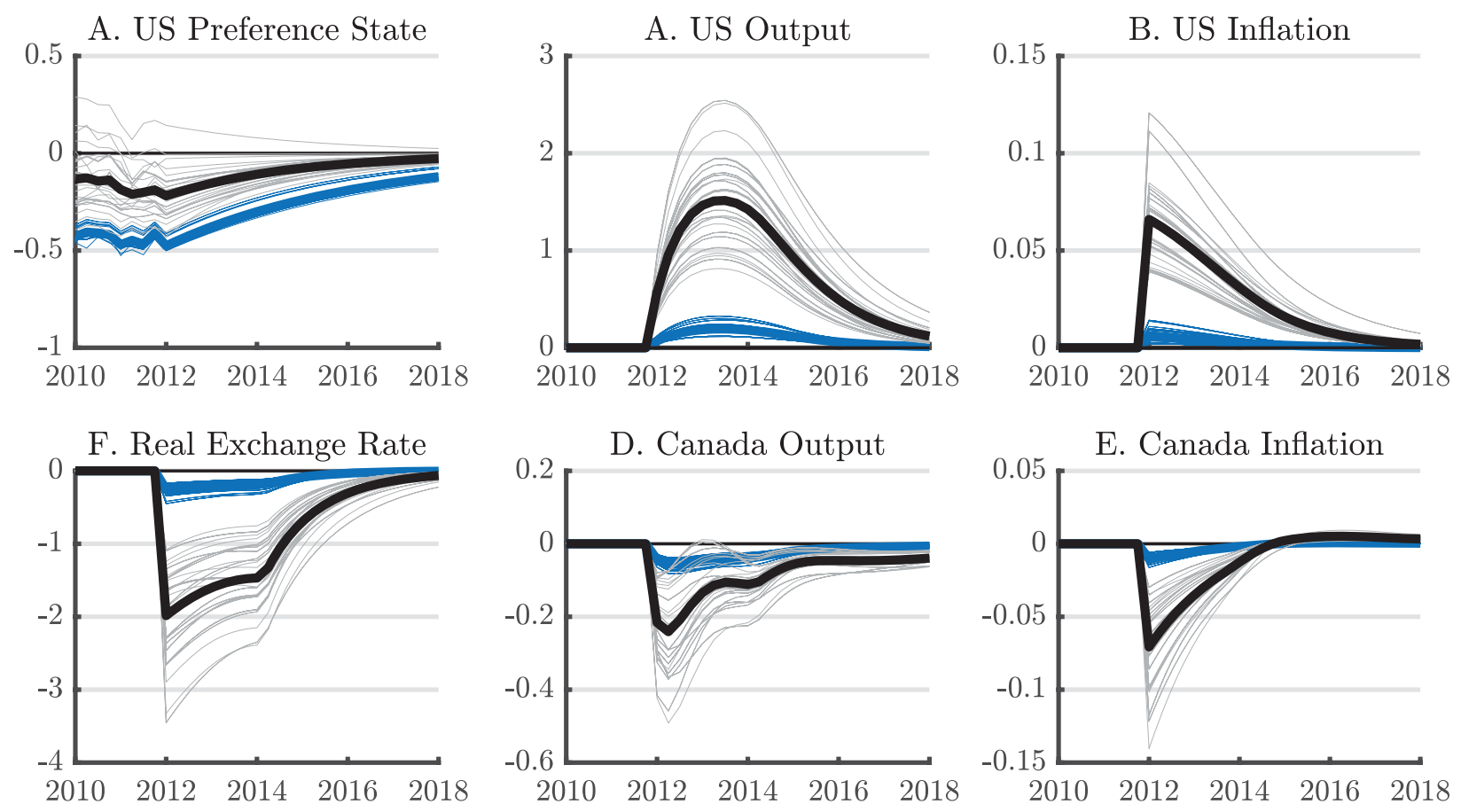
Figure 9: Percentage Change in Output With No Forward Guidance in US and Canada
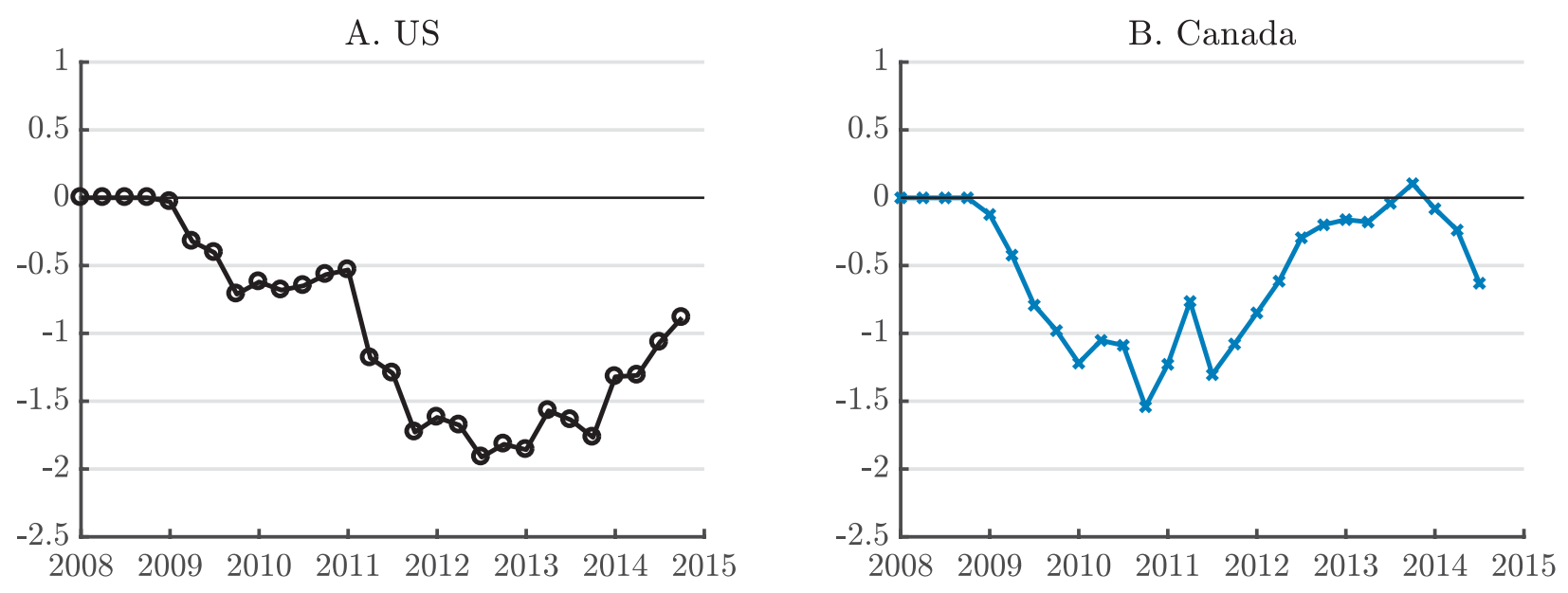
Figure 10: Percentage Change in Output With No Forward Guidance in US Only
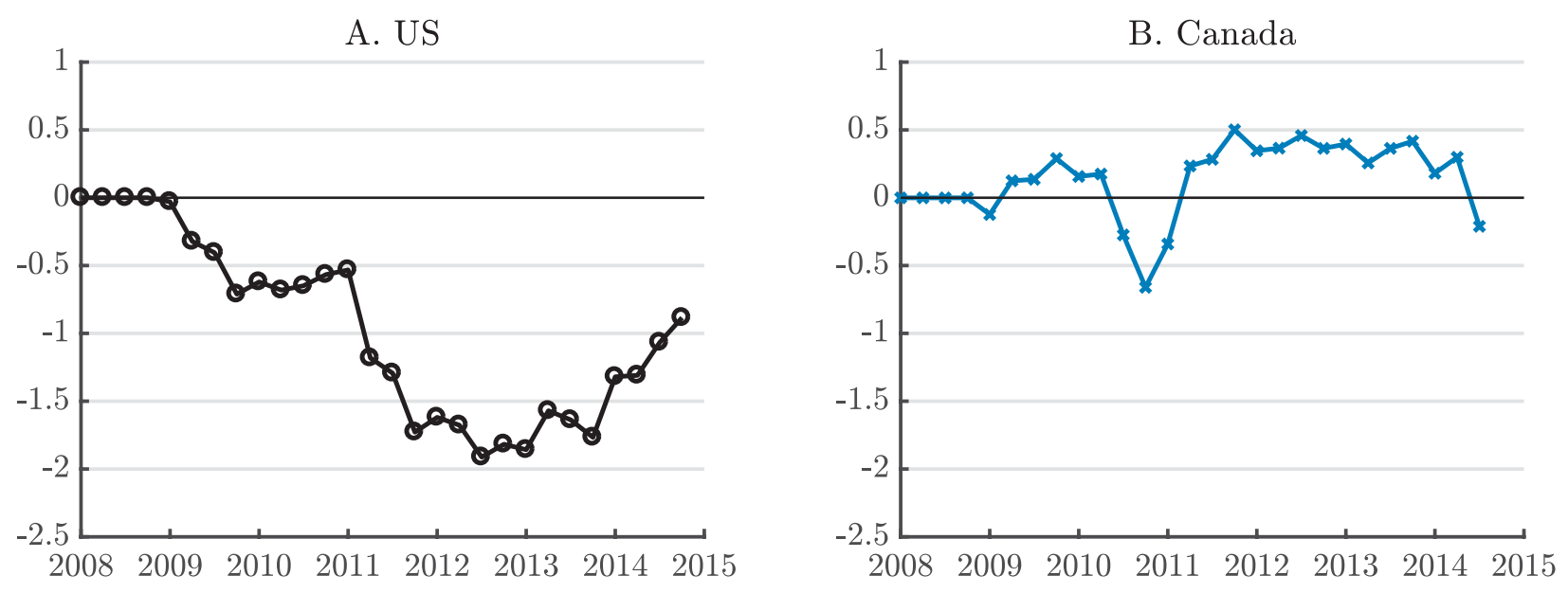